\title{
Reversible optical control of the metal-insulator transition across the epitaxial heterointerface of a $\mathrm{VO}_{2} / \mathrm{Nb}: \mathrm{TiO}_{2}$ junction
}

\author{
Yuanjun Yang ${ }^{1 *}$, Guilin Wang ${ }^{1}$, Wenyu Huang ${ }^{1}$, Cangmin Wang ${ }^{1}$, Yingxue Yao ${ }^{1}$, Xiaoli Mao ${ }^{1}$, \\ Hui Lin ${ }^{1}$, Ting Zhang ${ }^{1}$, Huaili Qiu ${ }^{1}$, Zhongjun Li $^{1}$, Hui Zhang ${ }^{3 *}$, Yuewei Yin ${ }^{3}$, Jinhua Guo ${ }^{5}$, \\ Yong Guan, Wensheng Yan ${ }^{5}$, Zhenlin Luo, Chongwen Zou ${ }^{5}$, Yangchao Tian ${ }^{5}$, Gang Xiao, \\ Xiaoguang $\mathrm{Li}^{3}$ and Chen $\mathrm{Gao}^{2 *}$
}

\begin{abstract}
Optical control of exotic properties in strongly correlated electron materials is very attractive owing to their potential applications in optical and electronic devices. Herein, we demonstrate a vertical heterojunction made of a correlated electron oxide thin film $\mathrm{VO}_{2}$ and a conductive $0.05 \mathrm{wt} \% \mathrm{Nb}$-doped $\mathrm{TiO}_{2}$ single crystal, whose metal-insulator transition (MIT) across the nanoscale heterointerface can be efficiently modulated by visible light irradiation. The magnitude of the MIT decreases from $\sim 350$ in the dark state to $\sim 7$ in the illuminated state, obeying a power law with respect to the light power density. The junction resistance is switched in a reversible and synchronous manner by turning light on and off. The optical tunability of it is also exponentially proportional to the light power density, and a 320-fold on/off ratio is achieved with an irradiance of $65.6 \mathrm{~mW} \mathrm{~cm}$ below the MIT temperature. While the $\mathrm{VO}_{2}$ thin film is metallic above the MIT temperature, the optical tunability is remarkably weakened, with a one-fold change remaining under light illumination. These results are co-attributed to a net reduction $(\sim 15 \mathrm{meV})$ in the apparent barrier height and the photocarrier-injection-induced metallization of the $\mathrm{VO}_{2}$ heterointerface through a photovoltaic effect, which is induced by deep defect level transition upon the visible light irradiance at low temperature. Additionally, the optical tunability is minimal, resulting from the quite weak modulation of the already
\end{abstract}

metallic band structure in the Schottky-type junction above the MIT temperature. This work enables a remotely optical scheme to manipulate the MIT, implying potential uncooled photodetection and photoswitch applications.

Keywords: metal-insulator transition, $\mathrm{VO}_{2}$ thin film, optical control, strongly correlated electron material, photoswitch

\section{INTRODUCTION}

Strongly correlated electron materials exhibit complex emergent properties due to the entangling and competition among charge, orbital, spin, and lattice degrees of freedom $[1,2]$. One of the most attractive phenomena is the metal-insulator transition (MIT), which is of great scientific as well as technological interest for developing the next generation of energy-efficient optical and electronic devices [2]. Vanadium dioxide $\left(\mathrm{VO}_{2}\right)$ is such an archetypical strongly correlated oxide with a sharp MIT near room temperature $\left(\sim 68^{\circ} \mathrm{C}\right.$ in bulk) [3], across which pronounced changes in electrical, optical, magnetic and thermal properties occur [4]. Many studies have been devoted to finding the driving mechanisms behind its phase transition [3-5]. The focused argument lies in whether the structural phase transition (electron-phonon coupling) or electronic correlation (electron-electron in-

\footnotetext{
${ }^{1}$ Department of Physics, and Lab of Solid State Microstructures and Quantum Control, School of Electronic Science and Applied Physics and School of Microelectronics, Hefei University of Technology, Hefei 230009, China

${ }^{2}$ School of Physical Sciences, University of Chinese Academy of Sciences, Beijing 100049, China

${ }^{3}$ Hefei National Laboratory for physical Sciences at Microscale (HFNL), University of Science and Technology of China, Hefei 230026, China

${ }^{4}$ Department of Physics, Brown University, Providence, Rhode Island 02912, USA

${ }^{5}$ National Synchrotron Radiation Laboratory, University of Science and Technology of China, Hefei 230026, China

* Corresponding authors (emails: yangyuanjun@hfut.edu.cn (Yang Y); huiz@ustc.edu.cn (Zhang H); gaochen@ucas.ac.cn (Gao C))
} 
teraction) drives the MIT, known as the Peierls- or Motttype transition in $\mathrm{VO}_{2}[6,7]$. Since the MIT temperature of the $\mathrm{VO}_{2}$ is near room temperature and can easily be controlled by external stimuli, researchers have developed different avenues to modulate the MIT, such as light $[8,9]$, strain [10], thermal [11], and electric field [12]. Taking advantages of sustained advances in synthesis and fabrication techniques, $\mathrm{VO}_{2}$ in the form of thin film, microwire, nanobeam or ordered array has demonstrated promising applications in optical switches [13], detectors [14], Mott transistors [15], neuromorphic computing [16], resistive memories [17], electrochromic devices [18] and ion batteries [19].

In particular, optical control of the MIT in the correlated electron thin film $\mathrm{VO}_{2}$ is much more attractive from the perspective of basic scientific research and practical application [20,21]. Morrison et al. [22] observed a metastable state on a sub-picosecond scale with a monoclinic metal-like phase in the $\mathrm{VO}_{2}$ thin film by $800-\mathrm{nm}$ femtosecond laser excitation. Jager et al. [23] utilized fewfemtosecond extreme ultraviolet (UV) transient absorption spectroscopy to track the nonequilibrium dynamics across the MIT in the $\mathrm{VO}_{2}$ thin films. Recently, Otto et al. [5] used the near-infrared $800-\mathrm{nm}$ femtosecond laser pulse to stimulate two independent insulator-to-metal transformations in the $\mathrm{VO}_{2}$ thin films, which involve changes in lattice as well as electronic structures. Zhang et al. [24] reported that a laterally confined conductive pattern was inscribed into an otherwise insulating area in the epitaxial (001) $-\mathrm{VO}_{2} / \mathrm{TiO}_{2}$ thin film using UV light irradiation, inducing a decrease in the electrical resistivity of almost four orders of magnitude. These investigations are helpful to deepen the understanding of the MIT mechanism and also open the possibilities to control the MIT behaviors using UV and infrared light irradiation. However, the light illumination on the aforementioned single-layer films of $\mathrm{VO}_{2}$ easily induce the thermal-driven MIT (namely the photothermal effect), deteriorating the device performance remarkably [25]. In recent years, thin-film heterojunction structures based on $\mathrm{VO}_{2}$ are thus proposed to solve this problem, enabling a wireless, remote, reversible and ultrafast modulation of the MIT behaviors and photoelectric properties. Additionally, the wafer-scale $\mathrm{VO}_{2}$ thin film has tremendous potential for integration with other electronic materials [26], such as conventional semiconductors [27], metals [28]. Ahn et al. [27] demonstrated the existence of a notable photovoltaic effect in the $\mathrm{VO}_{2} / \mathrm{Nb}: \mathrm{TiO}_{2}$ heterojunction under the UV light illumination. However, they did not show how the MIT depends on the power density of the light. A half- sphere $\mathrm{Au} / \mathrm{VO}_{2}$ core-shell heterojunction was fabricated by Balin et al. [28], making a large reduction of the transition temperature of $\mathrm{VO}_{2}$ through the red-light-induced local plasmonics. More recently, integrating $\mathrm{VO}_{2}$ thin films with the emergent electronic materials, exfoliated two-dimensional (2D) layered materials [29,30], topological insulators [30], and so forth, is of much interest in the resultant contacts or heterojunctions toward realizing high-speed and multifunctional devices, although the optical control of the MIT has not been carried out in such materials yet. All these studies open the possibility of an optical-controllable scheme to manipulate the MIT behaviors of $\mathrm{VO}_{2}$ [28-30]. Overall, few experimental studies on the reversible MIT using optical control in the $\mathrm{VO}_{2}$-based heterojunction are available. In particular, broadening spectral response of the $\mathrm{VO}_{2}$-based heterojunction from the UV and infrared to visible light region is scarcely reported. Consequently, the visible-light control of the MIT behaviors is relatively lacking, which is much more desirable for practical photoelectronic devices based on $\mathrm{VO}_{2}$. Furthermore, optical control of the transport properties of the $\mathrm{VO}_{2}$-based heterojunction in the insulating as well as metallic states is still limited and the manipulating mechanism is not well understood so far.

In this paper, we construct a vertical epitaxial heterojunction by stacking a strongly correlated electron oxide thin film $\mathrm{VO}_{2}$ on an n-type, wide band-gap semiconductor $\mathrm{Nb}$-doped $\mathrm{TiO}_{2}$ single crystal. The $\mathrm{n}$-nand Schottky-type contacts can be controllably formed by thermally driven MIT in the $\mathrm{VO}_{2}$ thin film. Visiblelight control of the MIT behaviors and transport properties in such a heterojunction were comprehensively investigated. It was observed that the amplitude of the MIT change is noticeably reduced under the visible light irradiation below the MIT temperature. The tunability of the junction resistance is exponentially proportional to the light power density. We experimentally demonstrate that the junction resistance of the $\mathrm{VO}_{2} / \mathrm{Nb}: \mathrm{TiO}_{2}$ heterojunction can be reversibly switched upon turning on and off the visible light illumination. The aforementioned results are ascribed to the modulation of the interfacial electronic structure of the $\mathrm{VO}_{2}$ thin film due to photocarrier injection and reduction of the apparent barrier height through the photovoltaic effect, which can be understood by a new photoexcitation process under the visible light illumination. Furthermore, we propose a prototype of a $2 \mathrm{D}$ photodetector based on the vertical $\mathrm{VO}_{2} / \mathrm{Nb}: \mathrm{TiO}_{2}$ heterojunction. 


\section{EXPERIMENTAL SECTION}

\section{Sample preparation and device fabrication}

A nominal $\mathrm{Nb}$ concentration of $0.05 \mathrm{wt} \% \mathrm{TiO}_{2}$ single crystal (Shinkosha Co., Ltd., Japan) with the (001) surface was employed for $\mathrm{VO}_{2}$ film growth. The substrate was $10 \mathrm{~mm} \times 10 \mathrm{~mm} \times 0.5 \mathrm{~mm}$. Using reactive radio frequency (RF) magnetron sputtering techniques $[9,31]$, high-quality $\mathrm{VO}_{2}$ epitaxial thin films were prepared by sputtering a vanadium metal target with $60 \mathrm{~W}$ power at a pressure of $0.43 \mathrm{~Pa}$. The growth temperature was set to $440^{\circ} \mathrm{C}$ (thermal couple temperature). The $\mathrm{Ar}$ and $\mathrm{O}_{2}$ flow ratios were set to 52 and $1.2 \mathrm{sccm}$. A nominal thickness of $\mathrm{VO}_{2}$ thin film was approximately $32 \mathrm{~nm}$ by controlling the deposition time [32]. Sequentially, a 5-nm-thick Ti buffer layer was prepared on the surface of the $\mathrm{VO}_{2}$ thin film for Ohmic contact. Then, a 10-nm-thick Pt thin film was deposited on the Ti layer to form the top electrode for the current sensing. The 5-nm thickness for the $\mathrm{Ti}$ buffer layer and 10-nm thickness for the Pt layer were selected to ensure good semitransparency for the light illumination on the heterojunction [33,34]. The backside of the $\mathrm{Nb}: \mathrm{TiO}_{2}$ substrate was also covered by the $\mathrm{Pt} / \mathrm{Ti}$ layers to ensure Ohmic contact. We used standard photolithography and physical ion milling to pattern the multilayers into a circular disk with a diameter of $1 \mathrm{~mm}$. The depth of the disk was etched to the surface of the $\mathrm{Nb}$ : $\mathrm{TiO}_{2}$ substrate.

\section{Microstructural characterizations}

The surface topography of the $\mathrm{VO}_{2}$ thin films was checked by atomic force microscopy (AFM, Bruker Dimension Icon, Germany) in the ScanAsyst mode. The surface roughness (root mean square, RMS) was obtained by averaging the total surface area of the AFM image. The crystal structure of the $\mathrm{VO}_{2}$ thin films was partially characterized by X-ray diffraction (XRD) with $\mathrm{Cu} \mathrm{Ka}$ radiation (Rigaku SmartLab Film Version). The strain state in the (001) $-\mathrm{VO}_{2} / \mathrm{Nb}: \mathrm{TiO}_{2}$ heterojunctions was investigated by synchrotron radiation $\mathrm{X}$-ray reciprocal space mapping (RSM) on the BL14B1 endstation at Shanghai Synchrotron Radiation Facilities (SSRF) with a wavelength of $1.24 \AA$ [9,31]. The results were plotted in reciprocal lattice units (r.l.u.) using rutile $\mathrm{TiO}_{2}$ as a reference.

The heterointerfacial structure was further investigated by transmission electron microscopy (TEM). Cross-sectional specimens oriented along the $\mathrm{Nb}^{-\mathrm{TiO}_{2}}$ [010] direction were prepared for the TEM analysis using ion milling after mechanical thinning and precision polish- ing. High-angle annular dark-field (HAADF) imaging was performed using a probe-corrected transmission electron microscope (JEOL, JEM-ARM200CF) with a cold field-emission gun operated at a $200 \mathrm{kV}$ bias. The convergence angle for the electron probe was set to $22 \mathrm{mrad}$ and the inner angle of the HAADF detector was $90 \mathrm{mrad}$. The compositional elements of the heterojunction were further analyzed using an energy-dispersive Xray spectrometer attachment. Soft X-ray absorption spectroscopy (XAS) at the V L and O K edges was performed on the X-ray magnetic circular dichroism (XMCD) beamline (BL12B) at the National Synchrotron Radiation Laboratory (NSRL), Hefei. The base pressure was greater than $3.0 \times 10^{-10}$ Torr. The X-ray beam size was approximately $1.0 \mathrm{~mm} \times 3.0 \mathrm{~mm}$. Total electron yield (TEY) mode was adopted to collect the drain current from the $\mathrm{VO}_{2} / \mathrm{Nb}$ : $\mathrm{TiO}_{2}$ heterojunction.

\section{Optical and electrical property measurements}

The transport properties under light illumination were measured by the four-probe technique. The $\mathrm{VO}_{2} / \mathrm{Nb}: \mathrm{TiO}_{2}$ devices were mounted on the probe station. Two of the four probes softly contacted the top electrode, and the other two contacted the common bottom electrode. For all the optical and electrical property measurements, a bias voltage was applied and the current was sensed across the $\mathrm{VO}_{2} / \mathrm{Nb}: \mathrm{TiO}_{2}$ devices with a vertical geometry configuration. We used a 2410 (Keithley, USA) as a voltage source. The current was measured by a 2400 (Keithley, USA) as a sensing meter. The photocurrent response was evaluated by a 2450 meter (Keithley, USA). A green laser with a wavelength of $\sim 532 \mathrm{~nm}$ served as the excitation light source. The power of the laser was calibrated by an optical power meter (Model: PM100D, THORLABS, Germany).

\section{RESULTS}

\section{Microstructure and interfacial chemistry studies}

Fig. 1a shows the XRD pattern of a typical $\mathrm{VO}_{2} / \mathrm{Nb}: \mathrm{TiO}_{2}$ thin film by a normal line scan. Two sets of diffraction peaks were detected: the (001) and (002) peaks from the $\mathrm{Nb}: \mathrm{TiO}_{2}$ substrate with a rutile phase and the (002) peak from the $\mathrm{VO}_{2}$ thin film, suggesting that the thin film is highly oriented along the out-of-plane [001] direction of the $\mathrm{Nb}: \mathrm{TiO}_{2}$ substrate. The asymmetrical diffraction peaks were also collected to check the in-plane orientation of the thin film with respect to the substrate. As shown in Fig. 1b, the XRD $\Phi$ scans of (112) peaks of the substrate are each separated by $90^{\circ}$, which originates from 

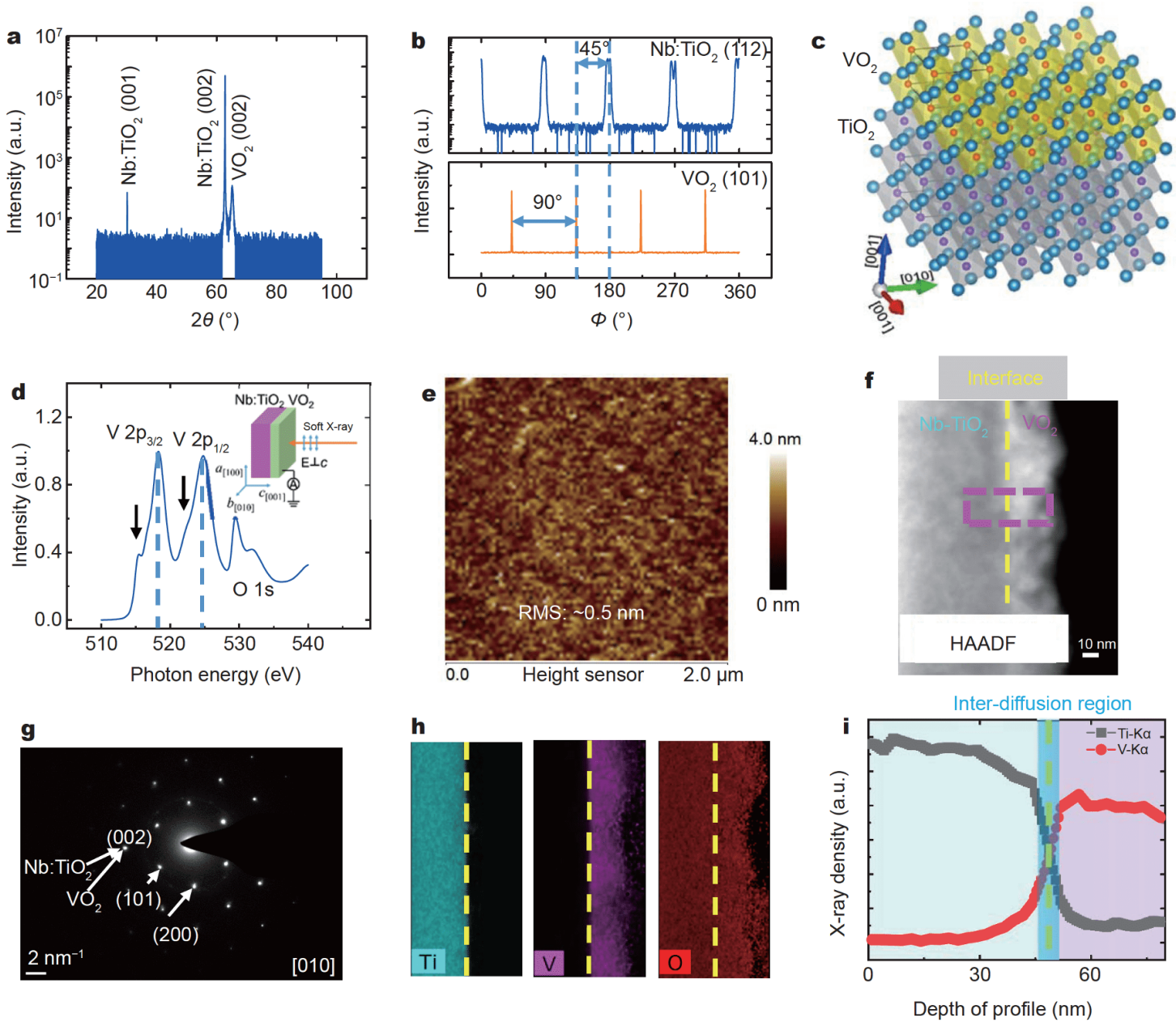

Figure 1 Microstructural properties of the $\mathrm{VO}_{2} / \mathrm{Nb}_{\mathrm{TiO}}$ heterointerface. (a) Normal XRD line scan of the $\mathrm{VO}_{2}$ thin film on the $\mathrm{Nb}$ :TiO $\mathrm{O}_{2}$ substrate.

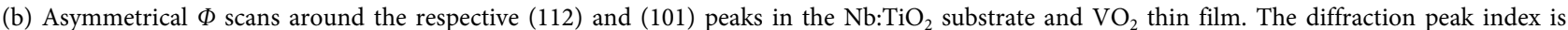
defined under the framework of tetragonal crystal symmetry in both $\mathrm{VO}_{2}$ and $\mathrm{Nb}_{\mathrm{TiO}}$. (c) Atomic schematic of the heterointerface of the $\mathrm{VO}_{2}$ film and $\mathrm{Nb}: \mathrm{TiO}_{2}$ substrate in a certain epitaxial manner. (d) Synchrotron radiation XAS spectrum of $\mathrm{V}$ L- and O K-edges of the $\mathrm{VO}_{2} / \mathrm{Nb}^{\mathrm{TiO}}{ }_{2}$ thin film. The spectrum was normalized to the maximum intensity. A schematic of the XAS measurement geometry is shown as the inset. (e) AFM image of the

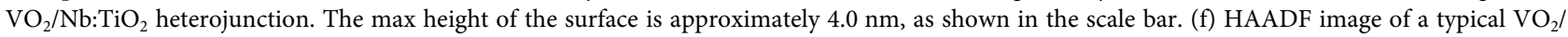
$\mathrm{Nb}: \mathrm{TiO}_{2}$ heterointerface. (g) Selected area electron diffraction (SAED) image of the heterojunction along the crystal axis [010] of the $\mathrm{Nb}^{\mathrm{T}} \mathrm{TiO}_{2}$ substrate, corresponding to the selected area labeled in (f). (h) Energy dispersive $\mathrm{X}$-ray spectroscopic images of the Ti, $\mathrm{V}$ and $\mathrm{O}$ elements across the heterointerface. (i) Line scans of the interfacial composition Ti and V elements across the heterointerface.

the nature of tetragonal symmetry of the substrate. For the $\mathrm{VO}_{2}$ thin film, four (101) peaks from the $\Phi$ scans are located at the azimuthal angles $45^{\circ}$ from those in the substrate labelled by a dashed line. The azimuthal separation $45^{\circ}$ is attributed to the different projection directions of the tetragonal $\mathrm{VO}_{2}(101)$ and $\mathrm{Nb}_{\mathrm{TiO}}(112)$ reflections with respect to the basal plane $\mathrm{Nb} \mathrm{TiO}_{2}(001)$ (see more details in Fig. S1 in the Supplementary information). Consequently, the $\mathrm{VO}_{2}$ thin film should coherently grow on the tetragonal $\mathrm{Nb}: \mathrm{TiO}_{2}$ crystal and has a similar symmetry as the substrate due to a good lattice match between them [4,9]. This symmetry implies the $\mathrm{VO}_{2}$ thin film is in a tetragonal-like phase due to substrate confinement. Therefore, the epitaxial relationships between the $\mathrm{VO}_{2}$ thin film and $\mathrm{Nb}: \mathrm{TiO}_{2}$ substrate are $[001]_{\mathrm{VO}_{2}} / /[001]_{\mathrm{TiO}_{2}}$ along the out-of-plane direction, and $[100]_{\mathrm{VO}_{2}} / /[100]_{\mathrm{TiO}_{2}}$ and $[010]_{\mathrm{VO}_{2}} / /[010]_{\mathrm{TiO}_{2}}$ along the inplane direction, which are schematically illustrated in Fig. 1c. Fig. 1d shows the soft X-ray absorption spectrum of the $\mathrm{V}$ L and $\mathrm{O}$ 1s edges, which was collected using TEY mode as demonstrated in the inset. The main peaks are 
located at $\sim 518$ and $524 \mathrm{eV}$ as indicated by dashed lines in Fig. $1 \mathrm{~d}$, corresponding to the $\mathrm{V} \mathrm{L}_{3}$ and $\mathrm{L}_{2}$ absorption edges that originate from the $2 p_{3 / 2} \rightarrow 3 d$ and $2 p_{1 / 2} \rightarrow 3 d$ transitions, respectively. The two shoulders near the main peaks are marked by arrows in Fig. 1d, which is a clear signature of the well-known $\mathrm{V}-\mathrm{V}$ dimerization in the insulating monoclinic $\mathrm{VO}_{2}$ (M1 phase) [5]. Furthermore, such a tetragonal-like $\mathrm{VO}_{2}$ thin film was checked in an insulating state by transport measurements in our previous work [35]. Therefore, the $\mathrm{VO}_{2}$ thin film in this work is essentially insulating with a monoclinic phase by epitaxial strain. Fig. 1e shows the AFM image of the surface of the $\mathrm{VO}_{2} / \mathrm{Nb}: \mathrm{TiO}_{2}$ heterojunction. The RMS roughness of the $\mathrm{VO}_{2}$ thin film on the $\mathrm{Nb}: \mathrm{TiO}_{2}$ substrate was statistically estimated as $\sim 0.5 \mathrm{~nm}$, indicating a good surface quality of the film.

To examine the interfacial microstructure, TEM was employed to check the crystal symmetry and interface chemistry. Fig. If shows a cross-sectional HAADF image of the heterojunction. The thickness of the $\mathrm{VO}_{2}$ thin film was estimated as $\sim 32 \mathrm{~nm}$, which is in line with the aforementioned time-controlled film deposition. Moreover, bumps and pits are observable on the $\mathrm{VO}_{2}$ surface, agreeing with the AFM characterization. Fig. $1 \mathrm{~g}$ shows a selected area electron diffraction (SAED) pattern from the interface region marked with a rectangular frame in Fig. 1f. The diffraction patterns of the $\mathrm{VO}_{2}$ film and $\mathrm{Nb}$ : $\mathrm{TiO}_{2}$ substrate are not significantly different. Three typical diffraction spots of the $\mathrm{VO}_{2}$ (200), (002) and (101) with a relatively weak intensity are located near those of the substrate, indicating that $\mathrm{VO}_{2}$ and $\mathrm{TiO}_{2}$ have very similar lattice constants and tetragonal symmetry. As a consequence, the orientation relationships between the crystallographic axes of the $\mathrm{VO}_{2}$ film and $\mathrm{Nb}: \mathrm{TiO}_{2}$ substrate are: $[002]_{\mathrm{VO}_{2}} / /[002]_{\mathrm{TiO}_{2}}$ (along the out-of-plane direction) and $[101]_{\mathrm{VO}_{2}} / /[101]_{\mathrm{TiO}_{2}}$ (along the in-plane direction), which further confirms the XRD results. The chemical composition at the interface between the $\mathrm{Nb}$ : $\mathrm{TiO}_{2}$ substrate and $\mathrm{VO}_{2}$ film was subsequently investigated by energy-dispersive $\mathrm{X}$-ray spectroscopy (EDS). Fig. 1h shows the elemental maps across the heterointerface, corresponding to the $\mathrm{V}-\mathrm{L}_{2,3}$ edges at $\sim 513$ and $\sim 521 \mathrm{eV}, \mathrm{Ti}-\mathrm{L}_{2,3}$ edges at $\sim 456$ and $\sim 462 \mathrm{eV}$, and the $\mathrm{O}-\mathrm{K}$ edge at $\sim 530 \mathrm{eV}$, respectively. The depth dependencies of $\mathrm{V}$ and Ti elements are shown in Fig. 1i, implying an inter-mixing layer with a 7-nm thickness across the heterointerface. The inter-diffusion region marked in Fig. 1i indicates the $\mathrm{Ti}$ and $\mathrm{V}$ elements interdiffuse between the $\mathrm{VO}_{2}$ film and $\mathrm{Nb}: \mathrm{TiO}_{2}$ substrate during film deposition at an elevated temperature, in agreement with previous work [36]. As a consequence, the heterointerface based on the epitaxial $\mathrm{VO}_{2} / \mathrm{Nb}: \mathrm{TiO}_{2}$ junction was constructed, enabling the promising optical control of MIT behaviors in a vertical geometry.

\section{Optical control of the MIT}

Next, we show that the MIT behavior is modulated by light illumination. Fig. 2a shows the schematic of a vertical $\mathrm{VO}_{2} / \mathrm{Nb}: \mathrm{TiO}_{2}$ heterojunction device after the standard lithographic process. The photoresponse of the device was investigated under light illumination using the four-probe technique in a vertical geometry, as shown in Fig. 2a. Although parent rutile $\mathrm{TiO}_{2}$ is a semiconductor with a gap of $\sim 3.0 \mathrm{eV}$ [37], the light $\mathrm{Nb}$-doping $\mathrm{TiO}_{2}$ exhibits a considerable absorption in the visible light region (see Fig. S2). The detailed mechanism of visible absorption is discussed in the following sections. A green laser with a wavelength of $532 \mathrm{~nm}$ was deliberately chosen for optical control of the MIT behaviors in the visible light region.

To ensure the photoresponse from the heterojunction device, the $\mathrm{Pt} / \mathrm{Ti}$ contact type was preliminarily analyzed (see Fig. S3) and Ohmic contact between the Ti metal and the insulating $\mathrm{VO}_{2}$ at low temperature as well as the metallic state above the MIT temperature can be expected [27,38]. As evidenced in Fig. S4, the current-voltage ( $I-V)$ characteristics across two $\mathrm{Pt} / \mathrm{Ti}$ contacts (measured after the $\mathrm{VO}_{2}$ film was deposited on the $\mathrm{TiO}_{2}$ substrate) are linear over the studied voltages, indicating good Ohmic contact between $\mathrm{Pt} / \mathrm{Ti}$ electrode and $\mathrm{VO}_{2}$ film. It is notable that the $\mathrm{Nb}: \mathrm{TiO}_{2}$ substrate itself does not show photoconductivity, indicating that the resistance change does not result from the substrate under light illumination. Therefore, the electrical transport properties should be mainly determined by the heterojunction of the device. The junction resistance $(R) v s$. temperature $(T)$ curves of the device for the representative light illumination with a series of power densities are shown in Fig. $2 \mathrm{~b}$. In the dark state, the junction resistance across the vertical heterointerface resembles MIT features similar to that in the $\mathrm{VO}_{2} / \mathrm{TiO}_{2}$ epitaxial thin films measured in a lateral electrode configuration $[9,36,39]$. The low-temperature insulating state transits across a thermal hysteretic MIT region to the metallic state, as marked by the dashed lines in Fig. 2b. Upon application of light, the junction resistance is gradually suppressed with increasing power density, but maintains the MIT characteristics in the temperature region studied. The net reduction of the junction resistance at the low-temperature insulating state 

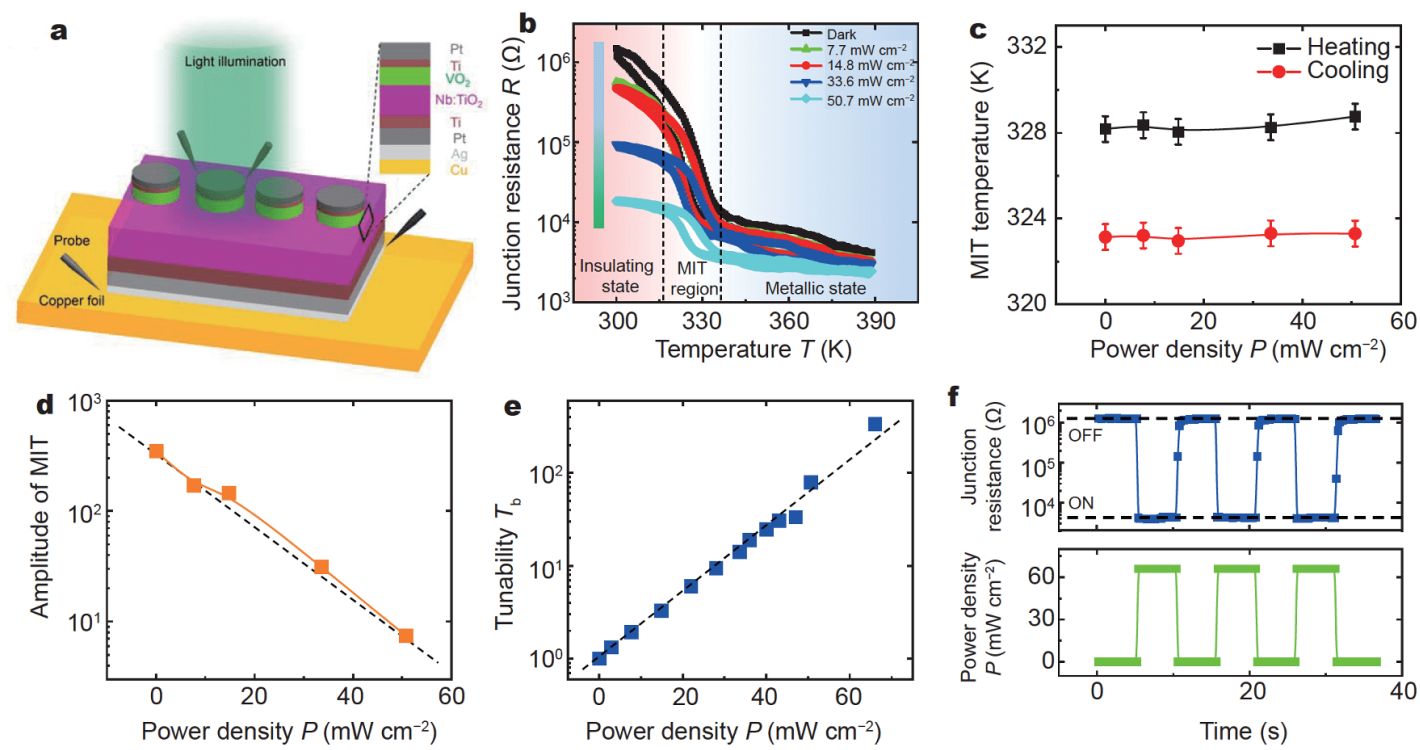

Figure 2 The device setup and heterointerfacial MIT controlled by light illumination. (a) Schematic figure of the $\mathrm{VO}_{2} / \mathrm{Nb}^{\mathrm{TiO}} \mathrm{T}_{2}$ heterojunction device and transport properties measured by the four-probe technique. The top $\mathrm{Pt} / \mathrm{Ti}$ layer on the $\mathrm{VO}_{2}$ thin film was defined as the positive electrode. The junction was illuminated by a 532-nm laser beam (spot size: $\sim 2.0 \mathrm{~mm}$ diameter). (b) The junction resistance $R v s$. temperature $T$ under laser illumination with a series of power densities $P$. A reverse bias $\sim 0.5 \mathrm{mV}$ was applied across the heterojunction. (c) Dependence of the MIT temperature on $P$. (d) Amplitude of the MIT change vs. $P$. (e) Optical tunability $\left(T_{\mathrm{b}}\right)$ of the junction resistance at $300 \mathrm{~K}$ as a function of $P$. (f) Junction resistance states controlled by a sequence of light illumination with an irradiance of $65.6 \mathrm{~mW} \mathrm{~cm}{ }^{-2}$. Here, the Ag layer is formed by silver paste to connect the bottom electrode $\mathrm{Pt}$ with the $\mathrm{Cu}$ layer, which is made of copper foil. Two probes softly contact the bottom $\mathrm{Cu}$ layer and the other two contact the top $\mathrm{Pt}$ electrode for the four-probe transport property measurements in the $\mathrm{VO}_{2} / \mathrm{Nb}_{\mathrm{TiO}}$ heterojunction device.

is much larger than that at the high-temperature metallic state. In addition, the MIT temperature was derived by differential processing (see Fig. S5) as 328.4 and $323.1 \mathrm{~K}$ for the heating and cooling processes, respectively $[9,40]$. It is interesting that the MIT temperature is unaffected in the heating and cooling processes by light irradiation, as shown in Fig. 2c. Notably, the MIT temperature here is a bit lower than that $(\sim 340 \mathrm{~K})$ of the bulk $\mathrm{VO}_{2}$ thin films $[9,41,42]$, which originates from the electron delocalization of $\mathrm{V}-\mathrm{V}$ dimers due to strain-induced shrinking of the $c$-axis [9]. Since the in-plane lattice constant $a$ of $\mathrm{Nb}^{-\mathrm{TiO}_{2}}$ is larger than that of bulk $\mathrm{VO}_{2}$, the tensile strain along the in-plane direction and compressive strain along the outof-plane direction of the $\mathrm{VO}_{2}$ epitaxial thin film develop. Synchrotron radiation high-resolution XRD reciprocal space mapping around the spots $\mathrm{VO}_{2}(112)$ and $\mathrm{Nb}: \mathrm{TiO}_{2}$ (112) further confirms this conjuncture (see Fig. S6 and the notes in the Supplementary information). Fig. $2 \mathrm{~d}$ summarizes the magnitude of the MIT change ratio vs. the light power density $P$. The amplitude of the MIT, which is defined as $R(300 \mathrm{~K}) / R(380 \mathrm{~K})$, is approximately $\sim 350$ at the dark state and decreases to $\sim 7$ with a light irradiance of $50.7 \mathrm{~mW} \mathrm{~cm}^{-2}$. Moreover, the amplitude of the MIT is approximately an exponential function of $P$, which is guided by the dashed line in Fig. 2d. According to the unchanged MIT temperature, a surface heating effect during light irradiation should be excluded here [25] and hence cannot be responsible for the optical control of the MIT behaviors. We next focused on the junction resistance controlled by light illumination at low temperature of the $\mathrm{VO}_{2}$ in an insulting state. Fig. 2e shows the dependence of the optical tunability of the junction resistance at $300 \mathrm{~K}$ on $P$, which is defined as $T_{\mathrm{b}}=$ $R(P) / R(P=0)$. Hence, $T_{\mathrm{b}}$ is unity at the dark state. The junction resistance $R$ was $\sim 1.36 \times 10^{6} \Omega$ at the dark state and decreased to $\sim 4.23 \times 10^{3} \Omega$ at $65.6 \mathrm{~mW} \mathrm{~cm}^{-2}$ light irradiation. A resultant large optical tunability $T_{\mathrm{b}}$ was achieved, $\sim 320 . T_{\mathrm{b}}$ is roughly exponentially proportional to $P$, which is guided by the dashed line in Fig. 2e. Furthermore, the junction resistance can be simultaneously and reversibly switched from a high resistance state to a low one by a sequence of programmable light illumination, as shown in Fig. 2f, demonstrating a potential application in a photoswitch at room temperature [43]. It is notable that optical control of the junction resistance switching depends on the applied voltages. We provide another set of experimental results measured under a reverse bias $10 \mathrm{mV}$ in Fig. S7. 


\section{Transport characteristics under light illumination}

In order to reveal the mechanism of the optical control of MIT behaviors using a visible light excitation, we investigated the transport characteristics of the device. Fig. 3a and $\mathrm{c}$ show the transfer characteristic curves under different illumination power densities at 300 and $380 \mathrm{~K}$, respectively. Additional transfer curves under different temperatures across the MIT temperature are shown in Fig. S8 to illustrate the transport property evolution across the MIT.

The $\mathrm{VO}_{2} / \mathrm{Nb}: \mathrm{TiO}_{2}$ device clearly exhibits asymmetric diode-like behavior as the $\mathrm{VO}_{2}$ thin film in an insulating state, as well as in a metallic state. The rectification ratios were $\sim 13,000$ and 72 for the $\mathrm{VO}_{2}$ film in the insulating and metallic states, respectively, under an applied voltage of $\pm 1 \mathrm{~V}$. Therefore, a good rectified heterojunction formed between the $\mathrm{VO}_{2}$ film and $\mathrm{Nb}: \mathrm{TiO}_{2}$ substrate, regardless of whether the $\mathrm{VO}_{2}$ film is in an insulating or metallic state. This result is consistent with previous observations in $\mathrm{VO}_{2} / \mathrm{p}-\mathrm{GaN}$ [38], $\mathrm{MoS}_{2} / \mathrm{VO}_{2}$ [43] and $\mathrm{VO}_{2} /$ $\mathrm{Nb}: \mathrm{TiO}_{2}$ [27] heterojunctions. The rectification ratio hardly depends on the illumination power density in Fig. $3 \mathrm{a}$ and $\mathrm{c}$ at 300 and $380 \mathrm{~K}$ with the applied voltage more than $0.2 \mathrm{~V}$, which has not been found in the pre- vious studies $[27,43]$. Partially enlarged views of Fig. 3a and $c$ are correspondingly presented in Fig. $3 b$ and $d$. The zoomed-in transfer curves do not cross the zero current (voltage) point and shift toward a more negative current value even when the applied voltage (current) was zero under the light illumination. This is the photocurrent generation mechanism through the photovoltaic effect for separation of the electron-hole pairs operated by the internal electric field in the junction region based on the $\mathrm{VO}_{2} / \mathrm{Nb}: \mathrm{TiO}_{2}$ heterointerface [44]. The photovoltage and photocurrent generation mechanism are discussed in detail in the following section.

To quantitatively determine the photovoltaic effect in the heterojunction device, the short circuit current $I_{\mathrm{SC}}$ and open circuit voltage $V_{\mathrm{OC}}$ with respect to the incident power density $P$ are summarized in Fig. $3 e$ and $f$, respectively. In both the insulating and metallic states, the measured $I_{\mathrm{SC}}$ shows a linear dependency on $P$. The $V_{\mathrm{OC}}$ depends on $P$ in a logarithmic manner, as shown in Fig. 3f. The resultant linear increase in the $I_{\mathrm{SC}}$ and logarithmic increase in the $V_{\mathrm{OC}}$ with $P$ are appropriate for a photoexcited heterojunction with an ideal p-n configuration, demonstrating that the optical control of the junction resistance should be closely related to the pho-
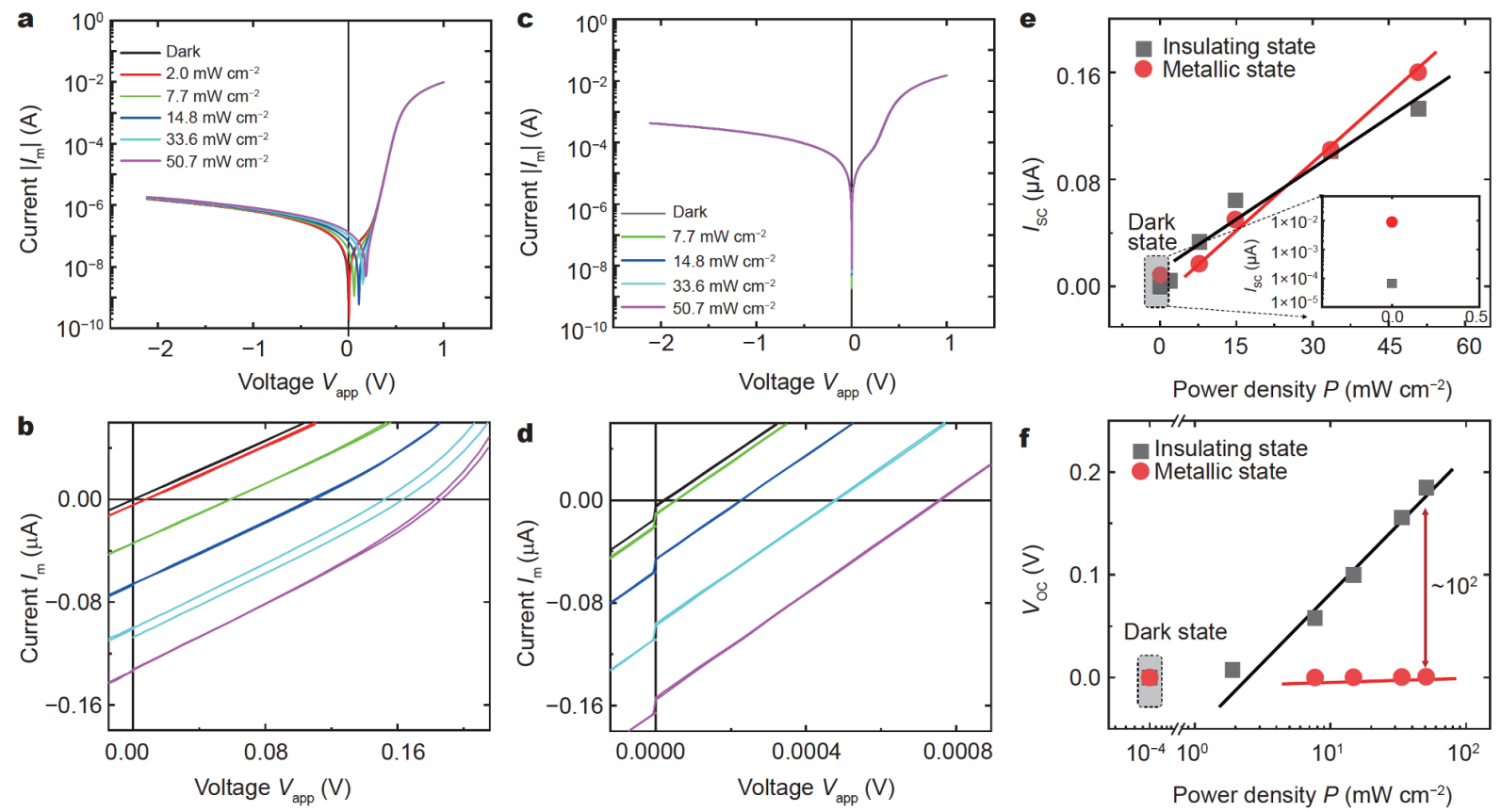

Figure 3 Transfer characteristics and photovoltaic effect in the $\mathrm{VO}_{2} / \mathrm{Nb}: \mathrm{TiO}_{2}$ device. (a, c) Experimental current-voltage characteristic curves of one typical device under the dark and illuminated conditions with a series of light power densities at 300 and $380 \mathrm{~K}$, respectively. The current $I_{\mathrm{m}}$ is plotted in log scale to show the rectification characteristics of the device. (b, d) The expanded $I$ - $V$ curves of the device on a linear scale to indicate the photoinduced current and voltage of the $\mathrm{VO}_{2}$ film in the insulating and metallic states, respectively. (e, f) Dependence of the short-circuit current $\left(I_{\mathrm{SC}}\right)$ and open-circuit voltage $\left(V_{\mathrm{OC}}\right)$ on the illumination power density with the $\mathrm{VO}_{2}$ in the insulating and metallic phases, respectively. 
tovoltaic effect. At $50.7 \mathrm{~mW} \mathrm{~cm}{ }^{-2}$ irradiation, $I_{\mathrm{SC}}$ and $V_{\mathrm{OC}}$ at the insulating state were $\sim 1.3 \times 10^{-7} \mathrm{~A}$ and $185 \mathrm{mV}$, respectively, and $\sim 1.6 \times 10^{-7} \mathrm{~A}$ and $0.75 \mathrm{mV}$, respectively, in the metallic state. Such pronounced $I_{\mathrm{SC}}$ and $V_{\mathrm{OC}}$ generated by light irradiation are indicative of the occurrence of a photogenerated carrier injection process in the device with the $\mathrm{VO}_{2}$ film in the insulating state. The slightly low $V_{\mathrm{OC}}$ is probably due to low photon energy using the visible illumination instead of UV irradiation as in the previous report [21]. However, the remarkable reduction of the $V_{\mathrm{OC}}$ in the device could originate from the phase transition of the $\mathrm{VO}_{2}$ film in a metallic phase at high temperature. At the dark state, $I_{\mathrm{SC}}$ (referred to as the dark current) in the $\mathrm{VO}_{2}$ insulating state is $\sim 6.67 \times 10^{-11} \mathrm{~A}$, which is two orders of magnitude lower than that $\left(\sim 9 \times 10^{-9} \mathrm{~A}\right)$ of the $\mathrm{VO}_{2}$ in the metallic state, as shown in the inset of Fig. 3e. This observation is a result of the increased thermal generation of electrons across the heterointerface with increasing temperature [45]. In the illuminated state, the main contribution to $I_{\mathrm{SC}}$ is the photogeneration of free carriers, and temperature should have a negligible effect on photogeneration in the established heterojunction [25]. In contrast, in the correlated electron heterojunction device of $\mathrm{VO}_{2} / \mathrm{Nb}: \mathrm{TiO}_{2}$ with the MIT, $I_{\mathrm{SC}}$ under illumination in the low-temperature insulating state is first higher than that at the high-temperature metallic state, but the $I_{\mathrm{SC}}$ changes with an opposite tendency as $P$ further increases. Consequently, the different evolution of $I_{\mathrm{SC}}$ at 300 and $380 \mathrm{~K}$ in Fig. 3e can be attributed to the phase transition as the $\mathrm{VO}_{2}$ film passes through the MIT region [46]. This result was confirmed by the large modulation of $V_{\mathrm{OC}}$ on the order of $\sim 10^{2}$, as marked in Fig. 3f, by comparing the $V_{\mathrm{OC}}$ at 300 and $380 \mathrm{~K}$. Notably, the electronic band structure of the $\mathrm{Nb}: \mathrm{TiO}_{2}$ substrate is inert to temperature [47]. Therefore, the distinct changes in the transport characteristics under light irradiation in the insulating and metallic states should be ascribed to the change in electronic band structure of the $\mathrm{VO}_{2}$. At $300 \mathrm{~K}$, the $\mathrm{VO}_{2}$ film is an n-type semiconductor with a narrow band gap $(\sim 0.6 \mathrm{eV})$. At $380 \mathrm{~K}$, the $\mathrm{VO}_{2}$ film is a metal. Therefore, a phase-controllable heterojunction type can be expected, indicating a novel avenue to exploit the exotic properties of the $\mathrm{VO}_{2}{ }^{-}$ based interface.

\section{DISCUSSION}

\section{Photocarrier injection process}

In this section, we provide details on the photocarrier injection across the interface between the $\mathrm{VO}_{2}$ film and
$\mathrm{Nb}: \mathrm{TiO}_{2}$ substrate. As mentioned in the Section of "Microstructure and interfacial chemistry studies", the MIT temperature is not altered by the light illumination, and hence the photoinduced structural phase transition from the normal insulating monoclinic to metallic rutile phase should be absent. If the photoinduced structural phase transition happens, the V-V atomic chain should change, resulting in modulation of the MIT temperature $[11,14]$. However, we did not observe this result. Therefore, we argue that the optical control of junction resistance and MIT behaviors is not due to the structural phase transition, but by the photoinduced carried injection and change of the energy band configuration due to the temperature-driven MIT in the $\mathrm{VO}_{2}$ thin films. Fig. $4 \mathrm{a}-\mathrm{c}$ show the energy bands of bulk $\mathrm{VO}_{2}$ in the $\mathrm{M} 1$ (monoclinic) and $\mathrm{R}$ (rutile) phase of the $\mathrm{Nb}: \mathrm{TiO}_{2}$ semiconductor, respectively. The work functions $\left(\Phi_{\mathrm{V}}\right)$ of the bulk $\mathrm{VO}_{2}$ thin film in the low-temperature insulating and high-temperature metallic states were $\sim 4.8$ and $4.7 \mathrm{eV}$, respectively [48]. The work function $\left(\Phi_{\mathrm{N}}\right)$ of $\mathrm{Nb}_{\mathrm{TiO}}$ single crystal was $\sim 4.1 \mathrm{eV}$ [49]. The electron affinities of the insulating $\mathrm{VO}_{2}\left(\chi_{\mathrm{V}}\right)$ and $\mathrm{Nb}: \mathrm{TiO}_{2}\left(\chi_{\mathrm{N}}\right)$ were $\sim 4.6$ and $3.7 \mathrm{eV}$, respectively $[43,50]$. The energy band gaps of the $\mathrm{M} 1 \mathrm{VO}_{2}\left(E_{\mathrm{gV}}\right)$ and $\mathrm{Nb}: \mathrm{TiO}_{2}\left(E_{\mathrm{gN}}\right)$ were $\sim 0.6$ and $3.0 \mathrm{eV}$, respectively, as shown in Fig. 4a and c [37,48]. Lightly doped $\mathrm{Nb}$ cations substitute for $\mathrm{Ti}$ cations in the rutile $\mathrm{TiO}_{2}$ lattice and mainly exist as $\mathrm{Nb}^{5+}$ [51]. Therefore, $\mathrm{Nb}^{5+}$ works as an n-type dopant in the $\mathrm{TiO}_{2}$ lattice and generates additional carriers in the conduction band (CB), producing a shallow energy level at $\sim 0.1 \mathrm{eV}$ below the $\mathrm{CB}$ maximum (CBM). The Fermi level calculated from the donor density was $\sim 0.4 \mathrm{eV}$ below the $\mathrm{CBM}$, as shown in Fig. 4c. Many theoretical and experimental studies have shown that the host $\mathrm{Ti}^{4+}$ ions are reduced to $\mathrm{Ti}^{3+}$ ions by slightly doping $\mathrm{Nb}(0.05 \mathrm{wt} \%$ in this work $)$, and oxygen vacancies are introduced because of charge compensation [52-54]. The resultant deep defect level is located in the gap below the CBM at $\sim 1 \mathrm{eV}$, as shown in Fig. $4 c$, with a spreading feature of the gap state. The spreading width of the $\mathrm{O}^{2-}$ and $\mathrm{Ti}^{3+}$ deep gap states is approximately $\sim 0.4 \mathrm{eV}$, which was experimentally checked by photoemission and scanning tunneling microscopy studies in previous literature [51]. Fig. 4d shows the dominant light absorption process of the rutile $\mathrm{Nb}$ : $\mathrm{TiO}_{2}$ semiconductor under 532-nm laser excitation indicated by a green arrow. An electron is excited from valence band (VB) to the deep defect level and thus the pair of the photogenerated electron and hole is formed, as shown by green arrow in Fig. 4d. The detailed optical absorption processes are shown in Fig. S9. 

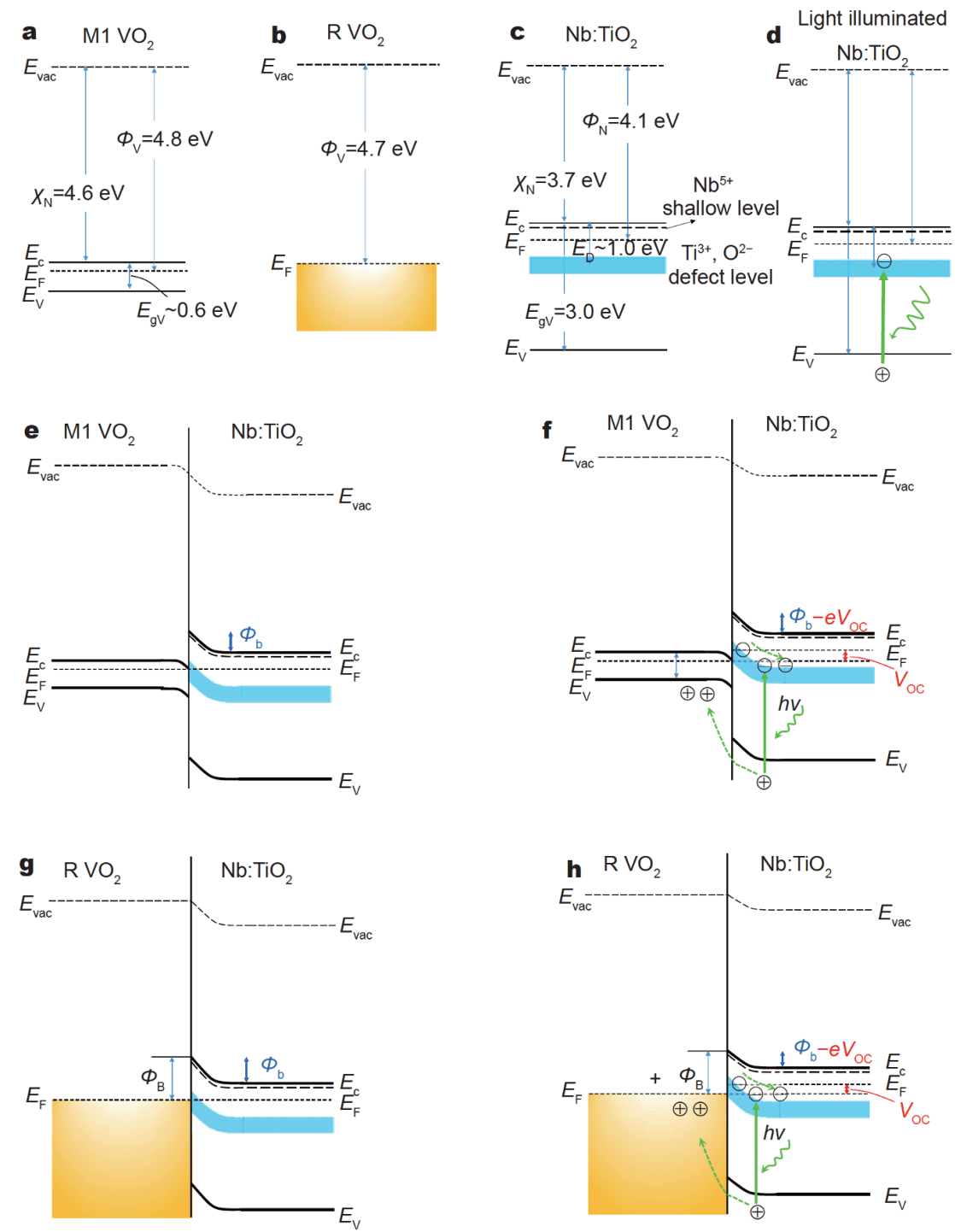

Figure 4 Energy band alignment of the $\mathrm{VO}_{2} / \mathrm{Nb}_{\mathrm{TiO}}$ heterojunction. (a-d) Energy band diagrams of the isolated $\mathrm{VO}_{2}$ in the insulating and metallic states, n-type $\mathrm{Nb}: \mathrm{TiO}_{2}$ without and with light illumination, from left to right, respectively. (e, f) Band alignments of the heterojunction with and without light illumination on the $\mathrm{VO}_{2}$ film in an insulating state, respectively. (g, h) Band alignments of the heterojunction with and without light illumination on the $\mathrm{VO}_{2}$ in a metallic state, respectively. The lengths of the line segment and arrow lines are not to scale for the energy level. The symbols + and - represent the photogenerated hole and electron, respectively.

According to Anderson's rule, as the insulating (or metallic) $\mathrm{VO}_{2}$ film and n-type $\mathrm{Nb}: \mathrm{TiO}_{2}$ crystal are brought together, the Fermi energies of the two materials must be equal at the thermal equilibrium state [55]. First, at low temperature, the $\mathrm{VO}_{2}$ with $\mathrm{M} 1$ phase is in an insulating state, and the heterojunction is formed with a type II band alignment through Fermi level matching, as shown in Fig. 4e, since the work function of $\mathrm{VO}_{2}$ film is larger than that of the $\mathrm{Nb}: \mathrm{TiO}_{2}$ substrate. From the electron affinity rule [56], we can deduce the built-in potential $\Phi_{\mathrm{b}}=\Phi_{\mathrm{V}}-\Phi_{\mathrm{N}}=4.8-4.1=0.7(\mathrm{eV})$, conduction band offset of $\Delta E_{\mathrm{c}}=\chi_{\mathrm{V}}-\chi_{\mathrm{N}}=4.6-3.7=0.9(\mathrm{eV})$, and valence band offset of $\Delta E_{\mathrm{v}}=\Delta E_{\mathrm{g}}-\Delta E_{\mathrm{c}}=(3.0-0.6)-0.9$ $=1.5(\mathrm{eV})$. As the heterojunction device is excited by $532-$ $\mathrm{nm}$ laser irradiation, the photovoltage induced by the light illumination is always positive for the $\mathrm{VO}_{2}$ film as observed in the Section of "Transport characteristics under light illumination", indicating that photogenerated holes should be selectively transferred to the $\mathrm{VO}_{2}$ side, with photogenerated electrons remaining in the $\mathrm{Nb}: \mathrm{TiO}_{2}$ 
side. We also excluded the contributions of photoexcitation process in the $\mathrm{VO}_{2}$ film to the photovoltaic effect using a $\mathrm{VO}_{2} / \mathrm{Nb}$-doped $\mathrm{SrTiO}_{3}$ heterojunction device as a control experiment (see Fig. S10). As a consequence, light absorption should occur and the resultant photocarriers must be generated in the $\mathrm{Nb}: \mathrm{TiO}_{2}$ substrate, but not in the $\mathrm{VO}_{2}$ film [21,57]. With the effect of the built-in potential, the electron-hole pairs are separated at the interfacial region, as shown in Fig. $4 \mathrm{f}$, resulting in the positive $V_{\mathrm{OC}}$ and negative $I_{\mathrm{SC}}$. It is worth noting that the deep gap states serve as the energy levels of electronaccepting defects to facilitate photovoltage and current generation. In addition, since the $\mathrm{Ti}^{3+} / \mathrm{O}^{2-}$ deep defect level is close to the conduction band, the captured electron is likely to be emitted before recombination occurs [58]. With increasing light power density, the transfer holes are injected into the $\mathrm{O} 2 \mathrm{p}$ band of the $\mathrm{VO}_{2}$ film, which must combine the counter-electrons located near the Fermi level (dominated by the $3 \mathrm{~d}$ band of the $\mathrm{VO}_{2}$ ). As a result, the resultant conducting hole carriers in the $\mathrm{d}_{\|}$band make the $\mathrm{VO}_{2}$ film near the heterointerface a metal, exhibiting optical control of the insulator-to-metal transition under light irradiation below the MIT temperature $[27,59]$. This case is different from the metallization triggered electrostatically on the surface of singlecrystal vanadium dioxide nanobeam via electrolyte gating as reported in ref. [60].

Second, at high temperature, as the $\mathrm{VO}_{2}$ film in a metallic state, since the work function of the $\mathrm{Nb}_{2} \mathrm{TiO}_{2}$ is smaller than that of the metallic $\mathrm{VO}_{2}$ film, a Schottky barrier is formed, as shown in Fig. 4g. From the electron affinity rule, we can obtain the built-in potential of such a Schottky-type heterojunction $\Phi_{\mathrm{b}}=\Phi_{\mathrm{V}}-\Phi_{\mathrm{N}}=4.7-4.1=$ $0.6(\mathrm{eV})$, and the Schottky barrier height $\Phi_{\mathrm{B}}=\Phi_{\mathrm{b}}+\left(\Phi_{\mathrm{N}}-\right.$ $\left.\chi_{\mathrm{N}}\right)=0.6+0.4=1.0(\mathrm{eV})$. Upon light irradiation, the positive $V_{\mathrm{OC}}$ develops through separation of the electronhole pairs by the built-in electric field, as shown in Fig. $4 \mathrm{~h}$. As a consequence, the barrier height $\Phi_{\mathrm{b}}$ is reduced by the photovoltage $V_{\mathrm{OC}}$, as shown in the n-n- and Schottky-type heterojunctions marked in Fig. $4 \mathrm{f}$ and h, respectively. The resultant photocurrent increases with the illuminated power density in both the insulating and metallic $\mathrm{VO}_{2} / \mathrm{Nb}: \mathrm{TiO}_{2}$ heterojunctions.

Based on the above theoretical analysis, the reduction of the barrier height in the metallic $\mathrm{VO}_{2} / \mathrm{Nb}: \mathrm{TiO}_{2}$ heterojunction is approximately $0.1 \mathrm{eV}$ with respect to the insulating case due to the work function change of the $\mathrm{VO}_{2}$ film [61]. Therefore, a larger dark current in the metallic $\mathrm{VO}_{2} / \mathrm{Nb}: \mathrm{TiO}_{2}$ device was observed in the Section of "Transport characteristics under light illumination".
Based on the energy band structure analysis, we discuss the dramatic reduction in the photovoltage (on the order of $\sim 1 \mathrm{mV}$ ) in the metallic $\mathrm{VO}_{2} / \mathrm{Nb}: \mathrm{TiO}_{2}$ device. It is plausible that there may be two reasons for this observation described in the Section of "Transport characteristics under light illumination". First, the electronhole pairs created by the irradiation of the metallic phase $\mathrm{VO}_{2}$ tend to recombine easily due to an increased recombination rate at high temperature [44]. Thus, the photovoltage is remarkably reduced. Second, the influence of the light illumination on the photovoltage is minimal in the already metallic band structure of the $\mathrm{VO}_{2}$ film. In the high-temperature metallic state, the carrier (electron) density and mobility of the $\mathrm{VO}_{2}$ thin film are enhanced by $\sim 1000$ and 10 times, respectively, compared with the insulating state (see Fig. S11). Consequently, the carriers at the $\mathrm{d}$ band of the $\mathrm{VO}_{2}$ film are sufficient and the Fermi level should not shift downward, even though the photoinduced holes inject into the metallic thin films. Therefore, the resultant $V_{\mathrm{OC}}$ is remarkably reduced in the Schottky-type $\mathrm{VO}_{2} / \mathrm{Nb}: \mathrm{TiO}_{2}$ device at high temperature. As an accompanying result, the photovoltage can only be modulated slightly and the junction resistance tunability is also very weak as the $\mathrm{VO}_{2}$ film is in the metallic state at high temperature. A similar behavior of a reduced photovoltage was also observed in metallic $\mathrm{YBa}_{2} \mathrm{Cu}_{3} \mathrm{O}_{x} / \mathrm{Nb}$ $\mathrm{SrTiO}_{3}$ and $\mathrm{VO}_{2} / \mathrm{Nb}: \mathrm{TiO}_{2}$ junctions upon UV light irradiation $[62,63]$.

\section{Photoinduced reduction of the effective barrier height}

To quantitatively evaluate the barrier change under different illumination levels in the device, we fit the $I-V$ transfer curves to extract the apparent barrier height and ideality factor. Supposing the thermionic emission (TE) is the dominant current transport mechanism, the $I-V$ curves can be described as $[38,56]$

$$
\begin{aligned}
& I=I_{\mathrm{TE}} \cdot \exp \left(\frac{q\left(V-I R_{\mathrm{b}}\right)}{n k_{\mathrm{B}} T}\right)\left(1-\exp \left(-\frac{q\left(V-I R_{\mathrm{b}}\right)}{k_{\mathrm{B}} T}\right)\right), \\
& I_{\mathrm{TE}}=S \cdot A^{*} \cdot T^{2} \exp \left(-\frac{q \Phi_{\mathrm{b}}}{k_{\mathrm{B}} T}\right), \\
& V^{\prime}=V-I R_{\mathrm{b}},
\end{aligned}
$$

where $S$ is the lateral area of the junction, $R_{\mathrm{b}}$ is the series resistance in the $\mathrm{VO}_{2} / \mathrm{Nb}: \mathrm{TiO}_{2}$ heterojunction, $k_{\mathrm{B}}$ is the Boltzmann constant, $A^{*}$ is the effective Richardson constant with a value of $\sim 156 \mathrm{~A} \mathrm{~cm}^{-2} \mathrm{~K}^{-2}$ for the $\mathrm{Nb}: \mathrm{TiO}_{2}$ substrate [64], $\Phi_{\mathrm{b}}$ is the effective (apparent) barrier height of the junction, $n$ is the ideality factor, $V^{\prime}$ is the voltage drop across the heterojunction, $I_{\mathrm{TE}}$ is the saturation cur- 
rent, $q$ is the magnitude of the electron charge, and $I R_{\mathrm{b}}$ is the voltage drop across the bulk $\mathrm{Nb}: \mathrm{TiO}_{2}$ substrate and $\mathrm{VO}_{2}$ film. This voltage drop is relatively small and neglected in the approximate region of applied voltage $(V>$ $0.1 \mathrm{~V}$ ) [56]. Based on the above Equation (1-3), the following expression can be derived:

$\ln \left(I /\left(1-\exp \left(\frac{q V}{k_{\mathrm{B}} T}\right)\right)\right)=\ln \left(I_{\mathrm{TE}}\right)+\frac{q V}{n k_{\mathrm{B}} T}$.

We linearly fitted Equation (4) as a function of the applied voltage $V$ and extrapolated the slope and intercept. Details are provided in Fig. S12. The ideality factor $n$ and apparent barrier height $\Phi_{\mathrm{b}}$ at different illumination levels can be calculated from the slope and intercept, respectively. Fig. 5a shows the ideality factor $n$ as a function of $P$. First, the ideality factor of the $\mathrm{VO}_{2}$ film in the low-temperature insulating phase is larger than that of the $\mathrm{VO}_{2}$ film in the high-temperature metallic phase. This result could be related to the lower interfacial state density of the $\mathrm{VO}_{2}$ film in the high-symmetry ( $\mathrm{R}$ phase) metallic phase than that in the low-symmetry (M1 phase) insulating phase. Similar behavior was also experimentally observed in $\mathrm{VO}_{2} / \mathrm{GaN}$ heterojunctions [56]. In addition, $n$ is close to unity in both cases, indicating that the TE transport mechanism dominates in the $n-n-$ and Schottky-type device in this work. Second, a clear decrease in $n$ as $P$ increases can be observed in the n-n-type $\mathrm{VO}_{2} / \mathrm{Nb}: \mathrm{TiO}_{2}$ heterojunction at low temperature, as shown in Fig. 5a. This result confirms the metallization of the $\mathrm{VO}_{2}$ in the vicinity of the heterointerface, as mentioned in this section. However, $n$ remains nearly unchanged in the case of the metallic $\mathrm{VO}_{2} / \mathrm{Nb}: \mathrm{TiO}_{2}$ heterojunction at high temperature, which is in accordance with the weak photovoltaic effect and un- regulated band structure of the $\mathrm{VO}_{2}$ film under light illumination, as discussed in this part of Sections of "Photocarrier injection process" and "Photoinduced reduction of the effective barrier height".

Fig. 5b shows that the apparent barrier height $\Phi_{\mathrm{b}}$ depends on $P$. First, in the dark state, $\Phi_{\mathrm{b}}$ of the high-temperature metallic $\mathrm{VO}_{2} / \mathrm{Nb}: \mathrm{TiO}_{2}$ heterojunction $(\sim 704 \mathrm{meV})$ is larger than that $(\sim 692 \mathrm{meV})$ of the lowtemperature insulating one, which is in accordance with the reduction in the work function when going through the insulator-to-metal transition $[48,61]$. Second, the net reduction of $\Phi_{\mathrm{b}}$ in the insulating heterojunction was approximately $15 \mathrm{meV}$, from $692 \mathrm{meV}$ in the dark state to $677 \mathrm{meV}$ with an irradiance of $50.7 \mathrm{~mW} \mathrm{~cm}^{-2}$. As noted in the Section of "Optical control of the MIT", the junction resistance is thus efficiently controlled by light illumination since the electrons flow though the low barrier more freely. In contrast, $\Phi_{\mathrm{b}}$ hardly changed with increasing $P$ when the $\mathrm{VO}_{2}$ film was in the metallic state. These two results show that the photocarrier injection can modulate the band structure of the $\mathrm{VO}_{2}$ film near the Fermi level at the low temperature, but cannot change the already metallic band structure at high temperature [59].

\section{Potential application based on the $\mathrm{VO}_{2} / \mathrm{Nb} \mathrm{TiO}_{2}$ heterojunction}

In this section, we propose and discuss a potential application based on the $\mathrm{VO}_{2} / \mathrm{Nb}: \mathrm{TiO}_{2}$ heterojunction with a vertical geometry. Fig. 6a shows the time domain photoresponse of the device by measuring the evolution of the photocurrent in response to ON/OFF and OFF/ON operations. The photocurrent was approximately $0.13 \mu \mathrm{A}$ with an irradiance of $65.6 \mathrm{~mW} \mathrm{~cm}^{-2}$ and the background current was approximately $0.42 \times 10^{-3} \mu \mathrm{A}$. The photo-
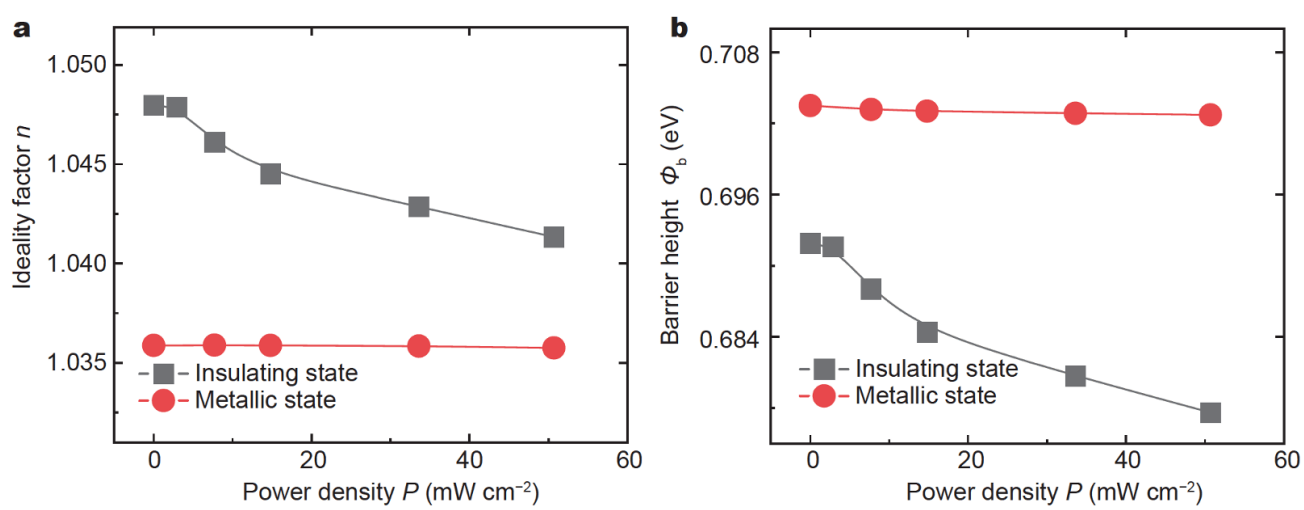

Figure 5 Optical control of ideality factor and barrier height. (a) Dependency of the ideality factor $n$ on the power density in the insulating (300 K) and metallic $(380 \mathrm{~K})$ states; (b) the apparent barrier height $\Phi_{\mathrm{b}}$ as a function of the light power density in the insulating (300 K) and metallic (380 K) states. 

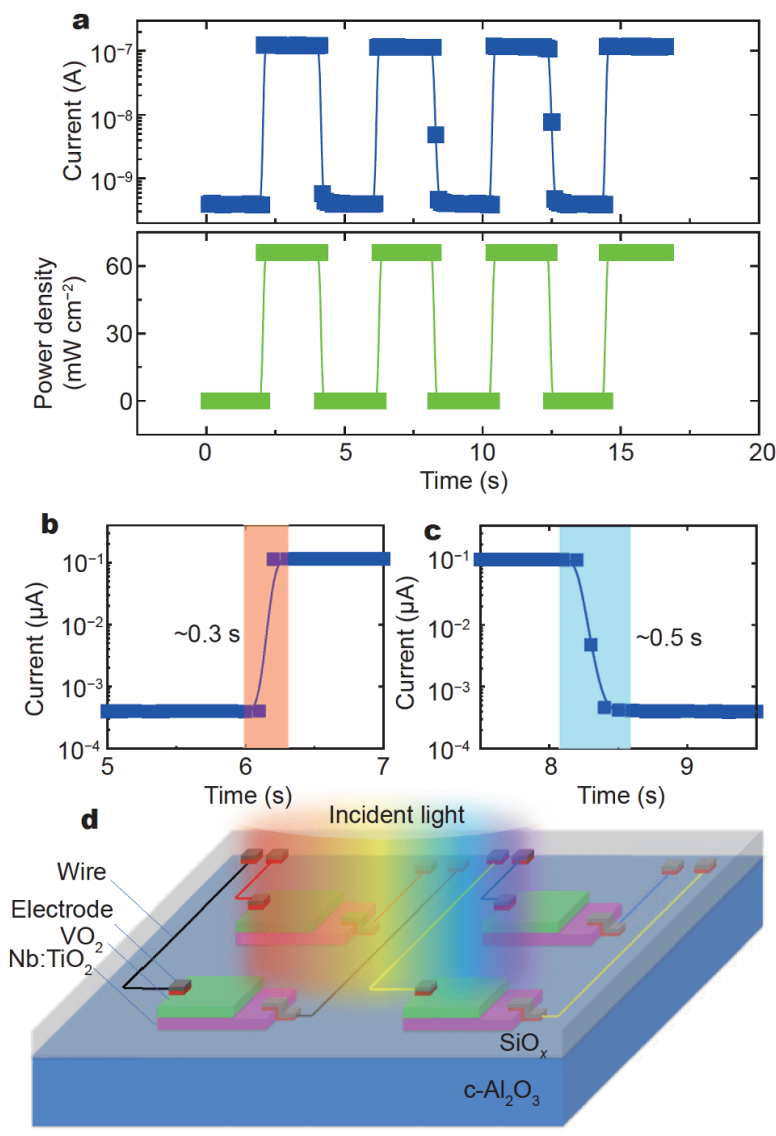

Figure 6 Potential photodetection application based on the vertical $\mathrm{VO}_{2} / \mathrm{Nb}: \mathrm{TiO}_{2}$ heterojunction. (a) The photocurrent is programmatically controlled by a sequence of light. (b, c) The photoresponse times in the rising and falling edges under illumination with a power density of $65.6 \mathrm{~mW} \mathrm{~cm}{ }^{-2}$, respectively. A reverse bias $\sim 0.5 \mathrm{mV}$ was applied across the heterojunction. (d) The proposed $2 \mathrm{D}$ photodetector based on allthin-film $\mathrm{VO}_{2} / \mathrm{Nb}: \mathrm{TiO}_{2}$ epitaxial heterojunctions.

current increased 309 times, further showing a 320 -fold tunability of the optical-controlled junction resistance by light irradiation. In addition, the photocurrent instantly increased before reaching an equilibrium state upon turning on the 532-nm light. The photocurrent decreased to the dark level immediately after the light was turned off. This process occurs quite reproducibly and synchronously follows the programmable sequence of the light. No degradation was observed after switching hundreds of times, as shown in Fig. 6a. It is mentionable that hundreds of photocurrent switchings in advance can ensure stability and durability of the $\mathrm{VO}_{2} / \mathrm{Nb}: \mathrm{TiO}_{2}$ heterojunction device. The corresponding response time upon turning on and off the light is shown in Fig. $6 \mathrm{~b}$ and c. The rise and decay time is determined as $\sim 0.3$ and $0.5 \mathrm{~s}$, respectively, in which the device reached roughly $10 \%$ to
$90 \%$ of the maximum photocurrent [65]. The rise time is overestimated owing to the temporal resolution limitation of the existing experimental conditions. The photocurrent increases upon turning on the light and quickly reaches the saturation, indicating the photo-excited electronic process of the charge separation and recombination in the heterojunction. This behavior is a typical feature of the photovoltaic effect rather than thermal effect in the device $[25,27]$. The decay time is longer than that in the rising process, which is ascribed to the $\mathrm{Ti}^{3+}$ and $\mathrm{O}^{2-}$ deep defect states in the $\mathrm{Nb}: \mathrm{TiO}_{2}$ surface and interfacial states in the $\mathrm{VO}_{2}$ thin film induced through Ti inter-diffusion from the substrate as evidenced in Fig. 1. This result is also in line with the case of the $\mathrm{VO}_{2} / \mathrm{WSe}_{2}$ heterostructures [30]. Additionally, since the temporal resolution is much longer than the speed of the MIT in $\mathrm{VO}_{2}$, which is intrinsically as fast as pico-seconds [3,8], the transport properties under light irradiation must be measured in an equilibrium state in the heterojunction device. However, in a conventional $\mathrm{VO}_{2} / \mathrm{Al}_{2} \mathrm{O}_{3}$ thin film device with lateral geometry, the rise and decay times were extended to $\sim 9.0$ and $13.0 \mathrm{~s}$, respectively. Moreover, the optical tunability of the resistance was $\sim 1.1$ times, which is two orders of magnitude lower than that of the $\mathrm{VO}_{2} / \mathrm{Nb}: \mathrm{TiO}_{2}$ heterojunction device. Response behaviors of the lateral device are presented in Fig. S13. Therefore, the response time of the heterojunction device is much shorter than that of the conventional lateral device. The fast response speed of the heterojunction device likely occurs because the built-in field quickly separates the photogenerated carriers in a vertical geometry configuration. Additionally, in the $\mathrm{VO}_{2} /$ $\mathrm{Al}_{2} \mathrm{O}_{3}$ lateral device, the photon interacts with the phonon of $\mathrm{VO}_{2}$ and a slower thermal dissipation modulates the resistive property. This process is commonly slower than the electronic process in the vertical heterojunction device through the photovoltaic effect $[66,67]$. Hence, the photoinduced thermal effect can be fairly neglected in this work, as mentioned in the Section of "Photoinduced reduction of the effective barrier height". Notably, the decay time for the thinner $\mathrm{VO}_{2} / \mathrm{Nb}: \mathrm{TiO}_{2}$ heterojunctions was approximately $0.36 \mathrm{~ms}$ after the UV light was turned off [21], indicating that our devices show room for future improvement. This difference results from the excitation light at different wavelengths and power densities, resulting in a different excitation process of $\mathrm{Nb}: \mathrm{TiO}_{2}$ and band structure modulation across the heterointerface by photocarrier injection. Furthermore, the longer rise and decay time in this work may also be related to the localization of the $\mathrm{Ti}^{3+}$ and $\mathrm{O}^{2-}$ deep defect states, which slow the charge transfer process upon turning on or off the 
light illumination $[68,69]$.

Next, we demonstrated the possibility of designing a photodetector based on the heterojunction device. A vertical $\mathrm{VO}_{2} / \mathrm{Nb}: \mathrm{TiO}_{2}$-based area detector is schematically shown in Fig. 6d, which is a sensor with multiple devices arranged in a single package. Details on the single photodetection component of such a conceptual area detector are presented in Fig. S14. This 2D detector could be used in a wide range of promising applications such as optical imaging, light position detection, and spectrophotometry. In the future, the facile integration of all-thin-film-based photodetectors can be expected with the conventional microelectronic process. Taking advantage of the state-ofthe-art techniques for $\mathrm{VO}_{2}$ and $\mathrm{TiO}_{2}$ thin film fabrication, we can design all-thin-film single photodetection unit on the $\mathrm{Al}_{2} \mathrm{O}_{3}$ substrates with epitaxial quality. As shown in Fig. $6 \mathrm{~d}$, the $\mathrm{Al}_{2} \mathrm{O}_{3}$ substrate was employed due to its high transparency in the $\mathrm{UV}$, visible and infrared regions. Moreover, the $c$-cut $\mathrm{Al}_{2} \mathrm{O}_{3}$ served as a good template for growing epitaxial $\mathrm{Nb}: \mathrm{TiO}_{2}$ thin films with the rutile phase structure. The $\mathrm{VO}_{2}$ film was successively deposited on the $\mathrm{Nb}: \mathrm{TiO}_{2}$ layer. After the sensor array was defined by a conventional lithography process, the transparent amorphous $\mathrm{SiO}_{x}$ layer was deposited for electric insulation and to protect the sensors. The sensor signals can be transferred to the external control circuit through the patterned electrode wires, as shown in Fig. 6d. For the component materials of the detector, $\mathrm{TiO}_{2}$ is the most common functional oxide and can be crystallized in the rutile phase with a band gap of $3.0 \mathrm{eV}$, providing excellent material properties such as an outstanding stability towards photon corrosion, nontoxicity, low cost, chemical stability and optical performance [69,70]. The electronic structures of $\mathrm{TiO}_{2}$ can be easily tailored through elementary doping and/or defect engineering to generate electronic states in the range of $0.5-1.5 \mathrm{eV}$ or below the valence band maximums (VBM) and CBM, providing light absorption from UV to visible light [70-73]. In this work, intermixing $\mathrm{V}$ and $\mathrm{Ti}$ across the heterointerface is one doping strategy that could facilitate the visible light absorption, as indicated in the Section of "Photocarrier injection process". Yang et al. $[47,74]$ used sputtering techniques to grow highly oriented $\mathrm{Nb}$-doping $\mathrm{TiO}_{2}$ thin films, indicating that an epitaxial wafer-scale film could be achieved in industrial production to prepare all-thinfilm detectors. This is good news for the proposed scheme in this work. In addition, the $\mathrm{VO}_{2}$ thin film can effectively absorb infrared light due to its narrow band structure $[28,75,76]$. For the same reason, the photoresponse can be broadened to the deep ultraviolet region, if the photon energy is larger than the energy gap of the $\mathrm{Nb}-\mathrm{TiO}_{2}$ substrate. The photoresponse under the violet and red light irradiance are also demonstrated in Fig. S15. Therefore, we can construct a 2D detector for imaging with the ability to cover the UV, visible and infrared light spectrum, which is desirable for uncooled optical detection and switching applications.

\section{CONCLUSIONS}

In summary, we constructed a correlated electron oxide $\mathrm{VO}_{2} / \mathrm{Nb}: \mathrm{TiO}_{2}$ heterojunction device with a vertical geometry, whose contact type can be modulated as an n-nand Schottky-type junction through the temperaturedriven MIT of the $\mathrm{VO}_{2}$ film. The optical control of the MIT and junction resistance switching was systematically investigated using visible light illumination. We observed that the magnitude of the MIT change exponentially depends on the light power density, and the MIT temperature does not change under light illumination. When the $\mathrm{VO}_{2}$ film was in an insulating state, the junction resistance switched in a reversible and synchronous manner upon turning the light on and off and the corresponding visible optical tunability $(\sim 320)$ was achieved with an irradiance of $65.6 \mathrm{~mW} \mathrm{~cm}{ }^{-2}$. In contrast, when the $\mathrm{VO}_{2}$ film was metallic above the MIT temperature, the optical tunability remarkably weakened with a factor of a onefold change in the junction resistance under light illumination. In the n-n-type heterojunction, a net reduction $(\sim 15 \mathrm{meV})$ of the apparent barrier height and the photocarrier-injection-induced metallization of the $\mathrm{VO}_{2}$ heterointerface through the photovoltaic effect ensure the great optical tunability of the MIT at low temperature. Additionally, the optical tunability is minimal, resulting from the quite weak modulation of the already metallic band structure in the Schottky-type junction above the MIT temperature. This work suggests a phase-controllable contact type based on the construction of a strongly correlated electron heterojunction. We also developed a remotely optical scheme to modulate the electronic structure and toggle the resistance states of the heterointerface of the $\mathrm{VO}_{2} / \mathrm{Nb}: \mathrm{TiO}_{2}$ heterojunction at room temperature, implying potential applications in uncooled photodetection and photoswitch.

Received 20 August 2020; accepted 25 November 2020;

published online 10 February 2021

1 Liu M, Sternbach AJ, Basov DN. Nanoscale electrodynamics of strongly correlated quantum materials. Rep Prog Phys, 2017, 80: 014501

2 Imada M, Fujimorih A, Tokura Y. Metal-insulator transitions. Rep 
Prog Phys, 1998, 70: 1039-1263

3 Wall S, Yang S, Vidas L, et al. Ultrafast disordering of vanadium dimers in photoexcited $\mathrm{VO}_{2}$. Science, 2018, 362: 572-576

4 Lee D, Chung B, Shi Y, et al. Isostructural metal-insulator transition in $\mathrm{VO}_{2}$. Science, 2018, 362: 1037-1040

5 Otto MR, René de Cotret LP, Valverde-Chavez DA, et al. How optical excitation controls the structure and properties of vanadium dioxide. Proc Natl Acad Sci USA, 2019, 116: 450-455

6 Kumar N, Rúa A, Fernández FE, et al. Ultrafast diffraction conoscopy of the structural phase transition in $\mathrm{VO}_{2}$ : Evidence of two lattice distortions. Phys Rev B, 2017, 95: 235157

7 Majid SS, Sahu SR, Ahad A, et al. Role of V-V dimerization in the insulator-metal transition and optical transmittance of pure and doped $\mathrm{VO}_{2}$ thin films. Phys Rev B, 2020, 101: 014108

8 Pashkin $\mathrm{A}$, Kübler $\mathrm{C}$, Ehrke $\mathrm{H}$, et al. Ultrafast insulator-metal phase transition in $\mathrm{VO}_{2}$ studied by multiterahertz spectroscopy. Phys Rev B, 2011, 83: 195120

9 Suess RJ, Bingham NS, Charipar KM, et al. Ultrafast phase transition dynamics in strained vanadium dioxide films. Adv Mater Interfaces, 2017, 4: 1700810

10 Yang Y, Mao X, Yao Y, et al. Thickness effects on the epitaxial strain states and phase transformations in $(001)-\mathrm{VO}_{2} / \mathrm{TiO}_{2}$ thin films. J Appl Phys, 2019, 125: 082508

11 Wang K, Cheng C, Cardona E, et al. Performance limits of microactuation with vanadium dioxide as a solid engine. ACS Nano, 2013, 7: 2266-2272

12 Jeong J, Aetukuri N, Graf T, et al. Suppression of metal-insulator transition in $\mathrm{VO}_{2}$ by electric field-induced oxygen vacancy formation. Science, 2013, 339: 1402-1405

13 Shi R, Shen N, Wang J, et al. Recent advances in fabrication strategies, phase transition modulation, and advanced applications of vanadium dioxide. Appl Phys Rev, 2019, 6: 011312

14 Sun $\mathrm{Y}$, Jiang L, Zhong $\mathrm{L}$, et al. Towards active plasmonic response devices. Nano Res, 2015, 8: 406-417

15 Nakano M, Shibuya K, Okuyama D, et al. Collective bulk carrier delocalization driven by electrostatic surface charge accumulation. Nature, 2012, 487: 459-462

16 Bohaichuk SM, Kumar S, Pitner G, et al. Fast spiking of a Mott $\mathrm{VO}_{2}$-carbon nanotube composite device. Nano Lett, 2019, 19: 6751-6755

17 Lee SH, Zhu X, Lu WD. Nanoscale resistive switching devices for memory and computing applications. Nano Res, 2020, 13: 12281243

18 Chen $\mathrm{S}$, Wang $\mathrm{Z}$, Ren $\mathrm{H}$, et al. Gate-controlled $\mathrm{VO}_{2}$ phase transition for high-performance smart windows. Sci Adv, 2019, 5: eaav6815

19 Jia D, Zheng K, Song $\mathrm{M}$, et al. $\mathrm{VO}_{2} \cdot 0.2 \mathrm{H}_{2} \mathrm{O}$ nanocuboids anchored onto graphene sheets as the cathode material for ultrahigh capacity aqueous zinc ion batteries. Nano Res, 2020, 13: 215-224

20 Liou YD, Chiu YY, Hart RT, et al. Deterministic optical control of room temperature multiferroicity in $\mathrm{BiFeO}_{3}$ thin films. Nat Mater, 2019, 18: 580-587

21 Eguchi R, Tsuda S, Kiss T, et al. Electronic structure of $\mathrm{VO}_{2} / \mathrm{TiO}_{2}$ : $\mathrm{Nb}$ upon photocarrier injection. Phys Rev B, 2007, 75: 073102

22 Morrison VR, Chatelain RP, Tiwari KL, et al. A photoinduced metal-like phase of monoclinic $\mathrm{VO}_{2}$ revealed by ultrafast electron diffraction. Science, 2014, 346: 445-448

23 Jager MF, Ott C, Kraus PM, et al. Tracking the insulator-to-metal phase transition in $\mathrm{VO}_{2}$ with few-femtosecond extreme UV transient absorption spectroscopy. Proc Natl Acad Sci USA, 2017, 114:
9558-9563

24 Zhang HT, Guo L, Stone G, et al. Imprinting of local metallic states into $\mathrm{VO}_{2}$ with ultraviolet light. Adv Funct Mater, 2016, 26: 66126618

25 Wang X, Gao H. Distinguishing the photothermal and photoinjection effects in vanadium dioxide nanowires. Nano Lett, 2015, 15: 7037-7042

26 Zhang HT, Zhang L, Mukherjee D, et al. Wafer-scale growth of $\mathrm{VO}_{2}$ thin films using a combinatorial approach. Nat Commun, 2015, 6: 8475

27 Ahn S, Dho J. Temperature dependent switching behavior and photovoltaic effect in $\mathrm{n}-\mathrm{n}$ semiconductor heterojunction $\mathrm{VO}_{2} / \mathrm{Nb}$ : $\mathrm{TiO}_{2}$. J Phys D-Appl Phys, 2019, 52: 485101

28 Balin I, Wang S, Wang P, et al. Enhanced transition-temperature reduction in a half-sphere $\mathrm{Au} / \mathrm{VO}_{2}$ core-shell structure: Local plasmonics versus induced stress and percolation effects. Phys Rev Appl, 2019, 11: 034064

29 Yamamoto M, Nouchi R, Kanki T, et al. Barrier formation at the contacts of vanadium dioxide and transition-metal dichalcogenides. ACS Appl Mater Interfaces, 2019, 11: 36871-36879

30 Luo H, Wang B, Wang E, et al. Phase-transition modulated, highperformance dual-mode photodetectors based on $\mathrm{WSe}_{2} / \mathrm{VO}_{2}$ heterojunctions. Appl Phys Rev, 2019, 6: 041407

31 Hong $\mathrm{B}$, Yang $\mathrm{Y}, \mathrm{Hu} \mathrm{K}$, et al. Strain engineering on the metalinsulator transition of $\mathrm{VO}_{2} / \mathrm{TiO}_{2}$ epitaxial films dependent on the strain state of vanadium dimers. Appl Phys Lett, 2019, 115: 251605

32 Hong B, Zhao J, Hu K, et al. Facile synthesis of various epitaxial and textured polymorphs of vanadium oxide thin films on the (0006)-surface of sapphire substrates. RSC Adv, 2017, 7: 2234122346

33 Axelevitch A, Gorenstein B, Golan G. Investigation of optical transmission in thin metal films. Phys Procedia, 2012, 32: 1-13

34 Macleod HA. Thin-Film Optical Filters. 3rd ed. Bristol and Philadelphia: Institute of Physics Publishing, 2001, 170

35 Qiu H, Yang M, Dong Y, et al. The tetragonal-like to rutile structural phase transition in epitaxial $\mathrm{VO}_{2} / \mathrm{TiO}_{2}(001)$ thick films. New J Phys, 2015, 17: 113016

36 Martens K, Aetukuri N, Jeong J, et al. Improved metal-insulatortransition characteristics of ultrathin $\mathrm{VO}_{2}$ epitaxial films by optimized surface preparation of rutile $\mathrm{TiO}_{2}$ substrates. Appl Phys Lett, 2014, 104: 081918

37 Yan W, Liu X. Niobium-Doped $\mathrm{TiO}_{2}$ : Effect of an interstitial oxygen atom on the charge state of niobium. Inorg Chem, 2019, 58: 3090-3098

38 Zhou Y, Ramanathan S. GaN/VO 2 heteroepitaxial p-n junctions: Band offset and minority carrier dynamics. J Appl Phys, 2013, 113: 213703

39 Laverock J, Jovic V, Zakharov AA, et al. Observation of weakened $\mathrm{V}-\mathrm{V}$ dimers in the monoclinic metallic phase of strained $\mathrm{VO}_{2}$. Phys Rev Lett, 2014, 121: 256403

40 Chen FH, Fan LL, Chen S, et al. Control of the metal-insulator transition in $\mathrm{VO}_{2}$ epitaxial film by modifying carrier density. ACS Appl Mater Interfaces, 2015, 7: 6875-6881

41 Lee J, Lee D, Cho SJ, et al. Epitaxial $\mathrm{VO}_{2}$ thin film-based radiofrequency switches with thermal activation. Appl Phys Lett, 2017, 111: 063110

42 Hu K, Yang Y, Hong B, et al. Thickness-dependent anisotropy of metal-insulator transition in (110) $-\mathrm{VO}_{2} / \mathrm{TiO}_{2}$ epitaxial thin films. J Alloys Compd, 2017, 699: 575-580

43 Oliva N, Casu EA, Yan C, et al. Van der Waals $\mathrm{MoS}_{2} / \mathrm{VO}_{2}$ het- 
erostructure junction with tunable rectifier behavior and efficient photoresponse. Sci Rep, 2017, 7: 14250

44 Kim DK, Hong SB, Jeong K, et al. P-N junction diode using plasma boron-doped black phosphorus for high-performance photovoltaic devices. ACS Nano, 2019, 13: acsnano.8b07730

45 Wang L, Cheng $\mathrm{S}, \mathrm{Wu} \mathrm{C}$, et al. Fabrication and high temperature electronic behaviors of $\mathrm{n}-\mathrm{WO}_{3}$ nanorods/p-diamond heterojunction. Appl Phys Lett, 2017, 110: 052106

46 Shukla N, Thathachary AV, Agrawal A, et al. A steep-slope transistor based on abrupt electronic phase transition. Nat Commun, 2015, 6: 7812

47 Yang X, Zhang MJ, Min Y, et al. Controllable formation of (004)orientated $\mathrm{Nb}: \mathrm{TiO}_{2}$ for high-performance transparent conductive oxide thin films with tunable near-infrared transmittance. ACS Appl Mater Interfaces, 2017, 9: 29021-29029

48 Sohn A, Kim H, Kim DW, et al. Evolution of local work function in epitaxial $\mathrm{VO}_{2}$ thin films spanning the metal-insulator transition. Appl Phys Lett, 2012, 101: 191605

49 Lee HY, Clark SJ, Robertson J. Calculation of point defects in rutile $\mathrm{TiO}_{2}$ by the screened-exchange hybrid functional. Phys Rev B, 2012, 86: 075209

50 Marques FC, Jasieniak JJ. Ionization potential and electron attenuation length of titanium dioxide deposited by atomic layer deposition determined by photoelectron spectroscopy in air. Appl Surf Sci, 2017, 422: 504-508

51 Morris D, Dou Y, Rebane J, et al. Photoemission and STM study of the electronic structure of $\mathrm{Nb}$-doped $\mathrm{TiO}_{2}$. Phys Rev B, 2000, 61: 13445-13457

52 Baumard JF, Tani E. Electrical conductivity and charge compensation in $\mathrm{Nb}$ doped $\mathrm{TiO}_{2}$ rutile. J Chem Phys, 1977, 67: 857-860

53 Yamamoto T, Ohno T. Screened hybrid density functional study on Nb- and Ta-doped $\mathrm{TiO}_{2}$. Phys Rev B, 2012, 85: 033104

54 Itakura $\mathrm{M}$, Niizeki $\mathrm{N}$, Toyoda $\mathrm{H}$, et al. Hall effect and thermoelectric power in semiconductive $\mathrm{TiO}_{2}$. Jpn J Appl Phys, 1967, 6: 311-317

55 Nagaveni K, Hegde MS, Madras G. Structure and photocatalytic activity of $\mathrm{Ti}_{1-x} \mathrm{M}_{x} \mathrm{O}_{2 \pm \delta}(\mathrm{M}=\mathrm{W}, \mathrm{V}, \mathrm{Ce}, \mathrm{Zr}, \mathrm{Fe}$, and $\mathrm{Cu})$ synthesized by solution combustion method. J Phys Chem B, 2004, 108: 2020420212

56 Zhou Y, Ramanathan S. Heteroepitaxial $\mathrm{VO}_{2}$ thin films on GaN: Structure and metal-insulator transition characteristics. J Appl Phys, 2012, 112: 074114

57 Hazu K, Ohtomo T, Nakayama T, et al. Lateral transport properties of $\mathrm{Nb}$-doped rutile- and anatase- $\mathrm{TiO}_{2}$ films epitaxially grown on c-plane GaN. Appl Phys Lett, 2012, 101: 072107

58 Kim S, Park JS, Walsh A. Identification of killer defects in kesterite thin-film solar cells. ACS Energy Lett, 2018, 3: 496-500

59 Petropoulos P, Kim HS, Richardson DJ, et al. Light-induced metallization at the gallium-silica interface. Phys Rev B, 2001, 64: 193312

60 Liu K, Fu D, Cao J, et al. Dense electron system from gate-controlled surface metal-insulator transition. Nano Lett, 2012, 12: 6272-6277

61 Ko C, Yang Z, Ramanathan S. Work function of vanadium dioxide thin films across the metal-insulator transition and the role of surface nonstoichiometry. ACS Appl Mater Interfaces, 2011, 3: 3396-3401

62 Hao FX, Zhang C, Liu X, et al. Photovoltaic effect in $\mathrm{YBa}_{2} \mathrm{Cu}_{3} \mathrm{O}_{7-\delta} /$ Nb-doped $\mathrm{SrTiO}_{3}$ heterojunctions. Appl Phys Lett, 2016, 109: 131104
63 Asakura D, Quilty JW, Takubo K, et al. Photoemission study of $\mathrm{YBa}_{2} \mathrm{Cu}_{3} \mathrm{O}_{y}$ thin films under light illumination. Phys Rev Lett, 2004, 93: 247006

64 Hikita Y, Kozuka Y, Susaki T, et al. Characterization of the Schottky barrier in $\mathrm{SrRuO}_{3} / \mathrm{Nb}: \mathrm{SrTiO}_{3}$ junctions. Appl Phys Lett, 2007, 90: 143507

65 Zhao Q, Wang W, Carrascoso-Plana F, et al. The role of traps in the photocurrent generation mechanism in thin InSe photodetectors. Mater Horiz, 2020, 7: 252-262

66 Giorgianni F, Sakai J, Lupi S. Overcoming the thermal regime for the electric-field driven Mott transition in vanadium sesquioxide. Nat Commun, 2019, 10: 1159

67 Shao Z, Cao X, Luo H, et al. Recent progress in the phase-transition mechanism and modulation of vanadium dioxide materials. NPG Asia Mater, 2018, 10: 581-605

68 Yamakata A, Vequizo JJM, Matsunaga H. Distinctive behavior of photogenerated electrons and holes in anatase and rutile $\mathrm{TiO}_{2}$ powders. J Phys Chem C, 2015, 119: 24538-24545

69 Di Valentin C, Pacchioni G, Selloni A. Reduced and n-type doped $\mathrm{TiO}_{2}$ : Nature of $\mathrm{Ti}^{3+}$ species. J Phys Chem C, 2009, 113: $20543-$ 20552

70 Naldoni A, Altomare M, Zoppellaro G, et al. Photocatalysis with reduced $\mathrm{TiO}_{2}$ : From black $\mathrm{TiO}_{2}$ to cocatalyst-free hydrogen production. ACS Catal, 2019, 9: 345-364

71 Inturi SNR, Boningari $\mathrm{T}$, Suidan $\mathrm{M}$, et al. Visible-light-induced photodegradation of gas phase acetonitrile using aerosol-made transition metal (V, Cr, Fe, Co, Mn, Mo, Ni, Cu, Y, Ce, and $\mathrm{Zr}$ ) doped $\mathrm{TiO}_{2}$. Appl Catal B-Environ, 2014, 144: 333-342

72 Lichterman MF, Hu S, Richter MH, et al. Direct observation of the energetics at a semiconductor/liquid junction by operando X-ray photoelectron spectroscopy. Energy Environ Sci, 2015, 8: 24092416

73 Mizushima K, Tanaka M, Asai A, et al. Impurity levels of irongroup ions in $\mathrm{TiO}_{2}$ (II). J Phys Chem. Solids, 1979, 40: 1129

74 Hazu K, Fouda A, Nakayama T, et al. Crystal phase-selective epitaxy of rutile and anatase $\mathrm{Nb}$-doped $\mathrm{TiO}_{2}$ films on a GaN template by the helicon-wave-excited-plasma sputtering epitaxy method. Appl Phys Express, 2010, 3: 091102

75 Liu M, Hwang HY, Tao H, et al. Terahertz-field-induced insulatorto-metal transition in vanadium dioxide metamaterial. Nature, 2012, 487: 345-348

76 Lee S, Meyer TL, Sohn C, et al. Electronic structure and insulating gap in epitaxial $\mathrm{VO}_{2}$ polymorphs. APL Mater, 2015, 3: 126109

Acknowledgements This work was supported by the Fundamental Research Funds for the Central Universities (108-4115100092), the National Key Research and Development Program of China (2016YFA0300102 and 2017YFA0205004), the National Natural Science Foundation of China (11775224, 11504358, 11804324 and 52072102), the Innovative Program of Development Foundation of Hefei Center for Physical Science and Technology (2018CXFX001), and the Natural Science Research Projects for the Colleges and Universities of Anhui Province (KJ2018A0660). The authors acknowledge the experimental support in the device fabrications and XAS spectra collection from beamlines BL07W and BL12B of National Synchrotron Radiation Laboratory (NSRL), respectively. The band alignment analysis from beamlines BL10B and BL11U of the NSRL by Qian Xu and Prof. Junfa Zhu was very helpful for this work. We also gratefully acknowledge Dr. Xingmin Zhang, Yueliang Gu, Prof. Xiaolong Li and Xingyu Gao for the $\mathrm{X}$-ray diffraction measurements at beamlines BL02U2 and BL14B1 at 
Shanghai Synchrotron Radiation Facilities (SSRF). We sincerely thank Shinkosha Co., Ltd. for the optical absorption measurement of the Nb$\mathrm{TiO}_{2}$ single crystals. The authors also sincerely thank Dr. You Zhou from Harvard University for valuable discussion on analyzing the transport properties in the heterojunction.

Author contributions Yang Y, Gao C and Zhang $\mathrm{H}$ conceived and designed this study. Yang Y, Mao X, Yao Y, Zhang T, Qiu H, Yan W and Zhang $\mathrm{H}$ co-designed and carried out the experiments. Wang G, Huang W, Wang C, Guo J, Guan Y, Luo Z and Tian Y prepared the thin films and fabricated the devices. Yang Y, Zou C, Lin H, Li Z, Yin Y, Li X and Xiao $G$ analyzed the experimental data and wrote the paper. All the authors discussed the results, revised and approved this manuscript.

Conflict of interest The authors declare that they have no conflict of interest.

Supplementary information Experimental details and supporting data are available in the online version of the paper.

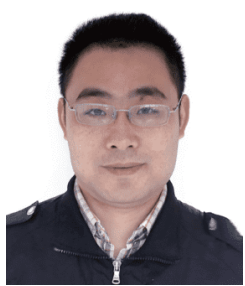

Yuanjun Yang received his BSc degree from Anhui University (2007) and $\mathrm{PhD}$ degree from the University of Science and Technology of China (USTC). Then, he worked as a postdoctoral fellow at the Department of Physics in USTC (2013) and then an associate professor at the National Synchrotron Radiation Laboratory. $\mathrm{He}$ has been an associate professor at Hefei University of Technology since 2016. His research interest is quantum control of correlated electron materials at the interfaces and heterojunctions.

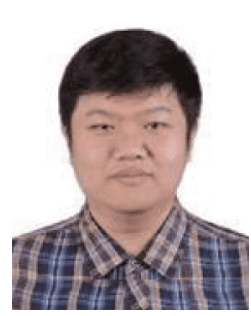

Hui Zhang received his $\mathrm{PhD}$ degree in condensed matter physics from USTC (2012). Then he joined the Institute for Quantum Computing, University of Waterloo as a postdoctoral fellow (2013). He has been a professor at Hefei National Laboratory for Physical Sciences at the Microscale in USTC since 2017. His research interests are novel two-dimensional materials, STM of low-dimensional materials at atomic scale and spin polarized and Josephson junction of magnetism topological insulator.

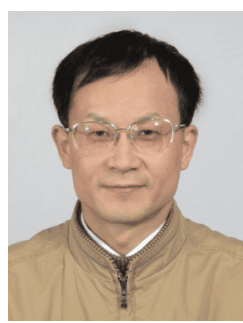

Chen Gao received his BSc (1984) and $\mathrm{PhD}$ (1990) degrees both from USTC. He worked as a professor at USTC since 2000, and then joined the School of Physical the Sciences, University of Chinese Academy of Sciences in 2020. He is currently a full professor in the University of Chinese Academy of Sciences. His research interests are high-throughput experimental methods for Materials Genome Initiative, correlated electron materials and applications of synchrotron radiation techniques in material science.

\section{$\mathrm{VO}_{2} / \mathrm{Nb}: \mathrm{TiO}_{2}$ 外延异质界面金属-绝缘体转变行为 的可逆光学调控}

杨远俊 ${ }^{*}$, 王桂林 ${ }^{1}$, 黄文宇 ${ }^{1}$, 王藏敏 ${ }^{1}$, 姚迎学 ${ }^{1}$, 毛小丽 ${ }^{1}$, 林辉 ${ }^{1}$, 张霆 $^{1}$, 仇怀利 ${ }^{1}$, 李中军 ${ }^{1}, 弓^{2}$ 汇 $^{3^{*}}$, 殷月伟 ${ }^{3}$, 郭金花 ${ }^{5}$, 关勇 $^{5}$, 间文盛 ${ }^{5}$, 罗震林 ${ }^{5}$, 邹崇文 ${ }^{5}$, 田扬超 ${ }^{5}$, 肖钢 ${ }^{4}$, 李晓光 ${ }^{3}$, 高琛 ${ }^{2 *}$

摘要 由于在光学和电子器件中的潜在应用, 强关联电子材料奇异 特性的光学调控研究引起了人们的广泛关注. 本文中, 我们设计和 演示了由关联电子氧化物外延薄膜二氧化钒 $\left(\mathrm{VO}_{2}\right)$ 和 $0.05 \mathrm{wt} \% \mathrm{Nb}$ 掺杂的导电 $\mathrm{TiO}_{2}$ 单晶构成的垂直异质结, 其在纳米尺度异质界面 上的金属-绝缘体转变 (metal-insulator transition, MIT) 可通过可见 光进行有效调控. 我们发现该异质结MIT幅度从黑暗状态的 350倍 降低到光照状态下的 7倍, 并且以幂指数规律依赖于光功率密度. 通过打开和关闭光照, 能够可逆地、同步地调控异质结的高、低 电阻态, 且该结电阻的光学调控力度也与光功率密度成幂指数依 赖. 在低于MIT温度下, 当光照功率密度为 $65.6 \mathrm{~mW} \mathrm{~cm}^{-2}$ 时, 其开/ 关比达到 320 倍; 当升高温度时, $\mathrm{VO}_{2}$ 薄膜转变为金属态时, 结电阻 的光学调控力度仅有 1倍的变化. 上述研究结果归因于异质结势 垒高度的降低(净减少 $15 \mathrm{meV}$ ) 和光伏效应诱导的异质界面处 $\mathrm{VO}_{2}$ 的金属化. 在低温下, 可见光光照激发 $\mathrm{Nb}: \mathrm{TiO}_{2}$ 深缺陷能级电子跃 迁, 诱导异质界面绝缘相 $\mathrm{VO}_{2}$ 金属化; 而在MIT温度以上, 异质结转 变为肖特基型结, 光照对金属相 $\mathrm{VO}_{2}$ 能带结构的调控减弱, 进而导 致结电阻的调控力度大幅降低. 该工作表明, 非接触式的光学手段 可以有效操纵关联电子材料 $\mathrm{VO}_{2}$ 的MIT行为, 有望在非致冷型的光 电检测和光电开关中得到广泛应用. 